National

Academy

NAS-NS

of

Sciences

National Research Council

NUCLEAR SCIENCE SERIES

Radiochemical Techniques

\title{
Liquid-Liquid \\ Extraction with \\ High-molecular-weight \\ Amines
}

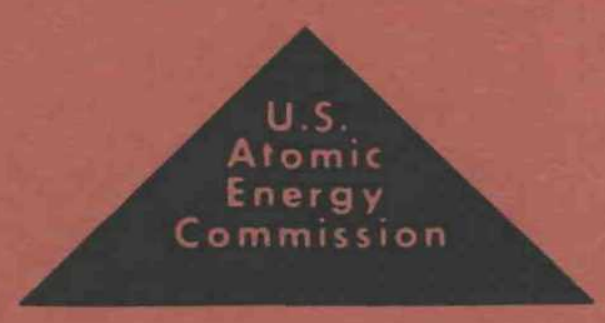




\section{COMMITTEE ON NUCLEAR SCIENCE}

L. F. CURTISS, Chairman

National Bureau of Standards
ROBLEY D. EVANS, Vice Chairman

Massachusetts Institute of Technology

J. A. DeJUREN, Secretary

Westinghouse Electric Corporation

\section{J. BORKOWSKI}

Oak Ridge National Laboratory

ROBERT G. COCHRAN

Texas Agricultural and Mechanical College

SAMUEL EPSTEIN

Californla Institute of Technology

U. FANO

National Bureau of Standards

HERBERT GOLDSTEIN

Nuclear Development Corporation of America
J. W. IRVINE, JR.

Massachusetts Institute of Technology

E. D. KLEMA

Northwestern University

W. WAYNE MEINKE

University of Michigan

J. J. NICKSON

Memorial Hospital, New York

ROBERT L. PLATZMAN

Laboratoire de Chimie Physique

D. M. VAN PATTER

Bartol Research Foundation

\section{LIAISON MEMBERS}

PAUL C. AEBERSOLD

Atomic Energy Commission

J. HOW ARD MCMILLEN

National Sclence Foundation
CHARLES K. REED

U. S. Air Force

WILLIAM E. WRIGHT

Office of Naval Research

\section{SUBCOMMITTEE ON RADIOCHEMISTRY}

W. WAYNE MEINKE, Chairman

University of Michigan

GREGORY R. CHOPPIN

Florida State University

GEORGE A. COWAN

Los Alamos Scientific Laboratory

ARTHUR W. FAIRHALL

University of Washington

JEROME HUDIS

Brookhaven National Laboratory

EARL HYDE

Unlversity of California (Berkeley)
HAROLD KIRBY

Mound Laboratory

GEORGE LEDDICOTTE

Oak Ridge National Laboratory

JULIAN NIELSEN

Hanford Laboratories

ELLIS P. STEINBERG

Argonne National Laboratory

PETER C. STEVENSON

University of Caltfornia (Livermore)

LEO YAFFE

MeGIII University

\section{CONSULTANTS}

NATHAN BALLOU

Naval Radiological Defense Laboratory
JAMES DeVOE

University of Michigan 


\section{DISCLAIMER}

This report was prepared as an account of work sponsored by an agency of the United States Government. Neither the United States Government nor any agency Thereof, nor any of their employees, makes any warranty, express or implied, or assumes any legal liability or responsibility for the accuracy, completeness, or usefulness of any information, apparatus, product, or process disclosed, or represents that its use would not infringe privately owned rights. Reference herein to any specific commercial product, process, or service by trade name, trademark, manufacturer, or otherwise does not necessarily constitute or imply its endorsement, recommendation, or favoring by the United States Government or any agency thereof. The views and opinions of authors expressed herein do not necessarily state or reflect those of the United States Government or any agency thereof. 


\section{DISCLAIMER}

Portions of this document may be illegible in electronic image products. Images are produced from the best available original document. 


\section{Liquid-Liquid Extraction with High-molecular-weight Amines}

FLETCHER L. MOORE

Oak Ridge National Laboratory

Oak Ridge, Tennessee

December 15, 1960

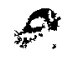

Subcommittee on Radiochemistry National Academy of Sciences - National Research Council 
, 


\section{FOREWORD}

The Subcommittee on Radiochemistry is one of a number of subcommittees working under the Committee on Nuclear Sclence within the National Academy of Sciences - National Research Counc1l. Its members represent government, industrial, and university laboratories in the areas of nuclear chemistry and analytical chemistry.

The Subcommittee has concerned itself with those areas of nuclear science which involve the chemist, such as the collection and distribution of radiochemical procedures, the establishment of specifications for radiochemically pure reagents, avallability of cyclotron time for service irradiations, the place of radlochemistry in the undergraduate college program, etc.

This serles of monographs has grown out of the need for up-to-date compliations of radiochemical information, procedures, and techniques. The subcommittee has endeavored to present a serles which w1ll be of maximum use to the working sclentist and which contains the latest avallable information. Each monograph collects in one volume the pertinent information required for radiochemical work with an individual element or with a specialized technique.

An expert in the particular radiochemical technique has written the monograph. The Atomic Energy Commission has sponsored the printing of the series.

The Subcommittee is confldent these publications will be useful not only to the radiochemist but also to the research worker in other fields such as physics, blochemistry or medicine who wishes to use radiochemical techniques to solve a specific problem. 


\section{INTRODUCTION}

This volume which deals with liquid-liquid extraction using high-molecular-welght amines is the first in a serles of monographs on radiochemical techniques which will parallel the series on the radiochemistry of the elements. The same general style is used in both series of monographs, beginning with general reviews of the technique, then a discussion of the principles involved, a detailed survey of applications to different systems, and finaliy a collection of selected procedures which use this technique as reported in the itterature.

This second series of techniques monographs will cover a number of radiochemical techniques which have not been reviewed elsewhere. Plans include revision of these monographs periodically as new information and procedures warrant. The reader is therefore encouraged to call to the attention of the author any published or unpublished material on extraction with high-molecular-weight amines which might be included in a revised version of the monograph. 


\section{CONTENTS}

I. General Reviews ................... I

II. Introduction and Principle ............. 1

III. General Survey of Applications . . . . . . . . . 6

A. Simple Acids ................. . . 6

B. Complex Metal Aclds . . . . . . . . . . . 8

1. Silver, Palladium, and Iead ......... 18

2. Calcium and Magnesium ............ . . 18

3. Polonium .................... 18

4. Zinc, Iron, Copper, Chromium, and Cobalt . . . . 18

5. Molybdenum ............... . . 21

6. Ruthenium ............... . . . 21

7. Technetium ................... 22

8. Titantum . . . . . . . . . . . . . . 23

9. Vanadium ................ . . 23

10. Thorium ................ 24

11. Zirconium and Hafnium ............ 25

12. Niobium and Tantalum . . . . . . . . . 26

13. Protactinium .............. . . . 29

14. Trivalent Lanthanide and Actinide Elements .... 31

15. Neptunium and Plutonium ........... 34

16. Uranium ................ . . . . 37

17. Miscellaneous Eixtractions......... 49

IV. Collection of Selected Procedures .......... 50 


\title{
Liquid-Liquid Extraction with High-molecular-weight Amines
}

\author{
FLETCHER L. MOORE \\ Oak Ridge National Laboratory* \\ Oak Ridge, Tennessee
}

I. GENERAL REVIEWS

Smith, E. I. and Page, J. E., "The Acid-Binding Properties of LongChain Aliphatic Amines," J. Soc. Chem. Ind. (London), 67, 48 (Feb. 1948).

Moore, F. L., "Long-Chain Amines - Versatile Acid Extractants," Anal. Chem. 29, 1660 (Nov. 1957).

Morrison, G. H. and Freiser, H., "Solvent Extraction in Analytical Chemistry - High-Molecular-Weight Amines," John Wiley and Sons, Inc., New York (1957), p. 150.

Coleman, C. F., Brown, K. B., Moore, J. G., and Crouse, D. J., "Solvent Extraction With Alkyl Amines," Ind. Eng. Chem. 50, 1756 (Dec. 1958).

II. INTRODUCTION AND PRINCIPLE

In recent years solvent extraction has emerged as one of the more popular separation techniques because of its ease, simplicity, speed, applicability both to tracer and macro levels of metal ions, and wide scope. (1) During the last twelve years, a new and versatile liquid-liquid extraction technique has been developed and an increasing number of useful applications appear in the literature. Organic solutions of high-molecularwelght amines and amine salts have been shown to be excellent extractants for mineral acids, many organic acids and complex metal acids from aqueous solutions. The analytical radiochemist and process development chemist

\footnotetext{
* Operatea for U. S. Atomic Energy Commission by Union Carbide Corporation.
} 
have found the technique valuable for a wide variety of separations.

Smith and Page ${ }^{(2)}$ first reported that the acid-binding properties of high-molecular-weight amines depend on the fact that acid salts of these bases are, in general, essentially insoluble in water but readily soluble in organic solvents, such as chloroform, benzene or kerosene. The extraction reactions are of the following ion-association type:

1. The organic solvent containing the amine can extract an aqueous acid to form an amine salt in the organic phase:

$$
\left(\mathrm{R}_{3} \mathrm{~N}\right)_{\mathrm{O}}+\mathrm{H}_{\mathrm{a}}^{+}+\mathrm{A}_{\mathrm{a}}^{-} \rightleftharpoons\left(\mathrm{R}_{3} \mathrm{NH}^{+} \mathrm{A}^{-}\right)_{\mathrm{O}}
$$

where $R_{3} N=$ a high-molecular-weight amine,

$\mathrm{A}^{-}=$anion of either a simple acid or a complex metal acid, as

$$
\begin{gathered}
\mathrm{FCCl}_{l^{-}}{ }^{-}, \\
0=\text { organic phase, } \\
a=\text { aqueous phase } .
\end{gathered}
$$

In alkaline solution, the extraction is reversed.

2. An amine salt in the organic phase can undergo anion exchange with an ion in the aqueous phase:

$$
\left(\mathrm{R}_{3} \mathrm{NH}^{+} \mathrm{A}^{-}\right)_{\mathrm{O}}+\mathrm{B}_{\mathrm{a}}^{-} \rightleftharpoons\left(\mathrm{R}_{3} \mathrm{NH}^{+} \mathrm{B}^{-}\right)_{\mathrm{O}}+\mathrm{A}_{\mathrm{a}}^{-}
$$

The order of preference in the amine organic solution is similar to that in anion exchange resins $-\mathrm{ClO}_{4}^{-}>\mathrm{NO}_{3}^{-}>\mathrm{Cl}^{-}>\mathrm{HSO}_{4}^{-}>\mathrm{F}^{-}$. (3)

The high-molecular-weight amines are often referred to as "liquid anion exchangers." In general, a strong analogy has been found between anion liquid-liquid extraction with high-molecular-weight amines and the solid anion exchange resins. The extraction curves have the same general form ${ }^{(4)}$ as is observed with solid anion exchangers. Thus, the previous intensive studies with the resins can be useful guides for extraction work. While this formal analogy with anion exchange resins is of great practical help to the chemist in the design of separations, it should not be overemphasized. The organic phase containing little or no water is quite dissimilar to an organic resin phase containing water. 
Fundamental studies of the amine extraction process, particularly for uranium, have been reported by Allen and co-workers! $5-11)$ fomin and co-workers, (12) and Carswell and Lawrance. (13) Investigations of the extraction mechanisms of zine, ${ }^{(4)}$ iron, ${ }^{(14)}$ and cobalt ${ }^{(15)}$ in the chloride-amine systems have been reported.

Most of the separation procedures described in this monograph are based on highly favorable separation factors and simple batch extractions are generally adequate for analytical purposes. Continuous countercurrent extraction techniques are used extensively for large scale isolation and purification purposes. For a comprehensive review on types of apparatus and extraction techniques, the reader is referred to Morrison and Freiser. (1) The specific references may be used to indicate the methods of extraction for the listed elements.

Essentlally all reported work has involved extractions at room temperatures $\left(20-30^{\circ} \mathrm{C}\right)$ for convenience. Extraction coefficients for uranium sulfate have been reported to decrease with rising temperature, varying with afferent amines, typically 20 to $30 \%$ per $10^{\circ} \mathrm{C}$. (3)

Brown and co-workers $(3)$ have found that the structure of the amine and the nature of the organic diluent exert a profound influence upon the extraction coefficient. While the amine class (primary, secondary, or tertiary) exerts an effect, these effects are strongly modified by the extent of branching of the alkyl groups and by the nature of the diluent. A branched-chain secondary amine behaves more like a straight-chain tertiary than like a straight-chain secondary amine. Highly branched chains generally interfere with efficient extraction, probably due to steric effects, but the branched-chain amines may be more compatible with the diluent; and, therefore, the net effect of chain branching on the extraction coefficient depends on the nature of the diluent. For instance, with chloroform, the uranfum(VI) extraction with either secondary or tertiary amine salts generally is in the order straight chain > branched chain, but with kerosene, the order reverses. 
Some amine salts are much less soluble in organic diluents than the corresponding amines. (3) In general, the amine salts show a decreasing solubility in the order sulfate, bisulfate, chloride, and nitrate and in the order tertiary, secondary, and primary amonium salt. The distribution ratio for the metal ion will be independent of its concentration if the netal species are all monomeric; for polymers, the distribution ratio will increase or decrease with metal ion concentration, depending on whether the polymeric species are more or less extractable than the monomeric ones. From aqueous sulfate solutions, uranium(VI) and iron(III) are examples of constant distribution ratios, while vanadium(V) and molybdenum(VI) show an increasing distribution ratio with increasing metal ion concentration. The hydrogen ion concentration may also effect the distribution ratio through the reaction with the complexing anion, e.g., $\mathrm{SO}_{4}{ }^{+}+\mathrm{H}^{+} \longrightarrow \mathrm{HSO}_{4}{ }^{-}$, or by effecting the hydrolysis of the metal ion.

Recent work ${ }^{(3)}$ suggests that in some cases, the amine salts in the organic diluent are associated into colloldal aggregates of nearly constant composition.

When one considers the numerous combinations of long-chain amines (primary, secondary, tertiary), the wide array of diluents available, and the many anionic aqueous systems that can be produced readily, it is seen that this technique offers great possibilities for chemical separations. Thus, for a given separation, a suitable aqueous system is produced such that the desired component is in anionic form and, therefore, extractable with a long-chain amine dissolved in a sultable diluent. By use of this technique, the general field of liquid-liquid extraction has been greatly increased. For instance, while isopropyl ether does not extract cobalt from strong hydrochloric acid solution, the sddition of a long-chain tertiary amine to the isopropyl ether results in excellent extraction of the anionic cobal The relative radiation stability of some of the high-molecular-weight amines over present solvents suggests many possible applications in radiochemical separations. For example, the radiation damage of Amberlite 
LA-I has been reported $(16)$ to be negligibly small under a total dose of $5 \times 10^{7} \mathrm{r}$. The effect of very high radiation doses on the decontamination performance of trilaurylamine-xylene has been found ${ }^{(17)}$ superior to that for trilaurylamine-Amsco combinations.

Table I shows the selectivity of high-molecular-weight amines in the sulfate system as reported by process development chemists. (18) This table lists some characteristic metal ion extraction coefficients

$$
\left(E_{a}^{O}(M)=\frac{(M)_{\text {organic }}}{(M)_{\text {aqueous }}}\right)
$$

for a number of elements which were extracted from sulfate solution by typical primary, secondary and tertiary amines. Most of the trivalent and tetravalent metal ions tested, if extracted at all, are extracted strongest by primary amines; the anount extracted decreases rapidily with

Table I

Selectivity of Amines as Extractants

system: $1 \mathrm{M} \mathrm{SO}_{4}^{=}, \mathrm{pH} 1$

\begin{tabular}{|c|c|c|c|}
\hline \multirow{2}{*}{ Element } & \multicolumn{3}{|c|}{ Amine Class } \\
\hline & Primary & Secondary & Tertiary \\
\hline$Y$ & so & & \\
\hline$Y(\mathrm{pH} \quad 0.2)$ & 0.2 & & \\
\hline $\mathrm{Ce}(\mathrm{IV})$ & $>50$ & $<0.1$ & \\
\hline $2 r$ & 300 & 40 & 10 \\
\hline$T h$ & 300 & 10 & $<0.1$ \\
\hline $\mathrm{U}(\mathrm{IV})$ & 2000 & 200 & 5 \\
\hline$v(V)$ & $<1$ & $<1$ & $<$ \\
\hline $\mathrm{V}(\mathrm{V})(\mathrm{pH} 2)$ & 30 & 30 & 30 \\
\hline $\operatorname{Mo}(\mathrm{VI})$ & 140 & 200 & 120 \\
\hline $\operatorname{Mo}(\mathrm{VI})(\mathrm{pH} 2)$ & 2000 & 3000 & 3000 \\
\hline $\mathrm{Fe}(\mathrm{III})$ & 40 & $<0.5$ & $<0.01$ \\
\hline Lanthanides (III) & 20 & $<0.1$ & $<0.01$ \\
\hline
\end{tabular}


secondary and tertiary amines. Vanadium, molybdenum, and uranium are extracted to about the same extent by each class of amine. Thus, useful selectivity between the two groups is possible. Thorium can be separated from uranium by extraction with primary amines, or uranium can be separated from thorium by extraction with tertiary or highly-branched secondary amines. HIgh separation factors are possible in each case. The extraction behavior of uranium(IV) is similar to that of thorium. From Table I, other useful separations are obrious to the chemist.

\section{GENERAL SURVEY OF APPLICATIONS}

\section{A. Simple Acids}

Smith and Page ${ }^{(2)}$ first demonstrated the efficient extraction of mineral acids and organic acids from aqueous solutions with long-chain amines dissolved in organic diluents. They found that tertiary amines were more efficient than secondary or primary amines and showed that strong acids could be extracted readily from mixtures with weak acids. Moore ${ }^{(19)}$ extended the technique to other acids and particularly complex metal acids. Table II shows the extraction of acids from aqueous solution with $5 \%$ methyl-din-octylamine dissolved in chloroform. A known quantity of acid was extracted with a slight excess of the solvent. The extracted acids could be stripped readily by shaking with aqueous solutions containing excess sodium hydroxide. Several of the organic acids extracted appreciably into chloroform containIng no amine, but the presence of the amine increased the extractability markedly. Thus, blank extractions of acetic, trichloroacetic and picric acids gave extractions of $7.2,10.2$ and $54 \%$, respectively. Under similar conditions, a solution of $5 \%$ tri-n-benzylamine-chloroform was found (19) to extract $50 \%$ hydrochloric acid, $68.4 \%$ nitric acid, $1.5 \%$ phosphoric acid and no sulfuric acid.

The successful application of the technique has been demonstrated (2) in the essentially quantitative recovery of hydrochloric acid from casein and gelatin hydrolysates. These workers suggested that the method may be employed in the following applications: 
Table II

Extraction of Acids From Aqueous Solution with $5 \%$ Methyl-di-n-octylamine-Chloroform

\begin{tabular}{|c|c|}
\hline Acid & Amount Extracted, $\%$ \\
\hline Hydrochloric & 98.0 \\
\hline Nitric & 98.0 \\
\hline Sulphuric & 98.0 \\
\hline Phosphoric & 76.5 \\
\hline Acetic & 75.8 \\
\hline Trichloroacetic & 98.7 \\
\hline Hydrofluoric & 87.1 \\
\hline Formic & 89.9 \\
\hline Glutaric & 86.9 \\
\hline Picric & $>96.0$ \\
\hline Fumaric & 95.9 \\
\hline Maleic & 97.5 \\
\hline Malic & 90.8 \\
\hline Lactic & 92.0 \\
\hline Oxalic & 98.0 \\
\hline Succinic & 90.0 \\
\hline p-Toluenesulphonic & 97.0 \\
\hline Aminoacetic & 0 \\
\hline Glutamic & 0 \\
\hline Gluconic & 0 \\
\hline Aspartic & 0 \\
\hline
\end{tabular}

Taken from data of Smith and Page ${ }^{(2)}$ and Moore. (19) 
1. Removal of mineral acids used in the hydrolysis of starch to glucose or of sucrose to invert sugar.

2. Removal of mineral acids used to catalyze a reaction, e.g., hydrolysis of esters, amides or nitriles.

3. Removal of a mineral acid produced in a reaction (e.g., hydrolysis of halogenated compounds), if necessary continuously, so as to maintain the pH closely to neutral.

4. Recovery of valuable organic acids from biological materials or fermentation Ilquors.

The extraction of lactic acid from aqueous solution with various alcohol or chloroform solutions of tri-n-amylamine and tri-n-octylamine has been described by Ratchford and co-workers. (20)

While no work has been reported yet on the application of the technique for the extraction of radioactive simple acids, this would appear to be a potentially useful area of investigation for the radiochemist.

B. Complex Metal Aclds

To date, most of the work with high-molecular-weight amines has involved the extraction and purification of uranium and plutonium by workers on various atomic energy projects. Hundereds of long-chain amines (molecular weight range, $\sim 250-600$ ) have been evaluated $(3)$ as metal extractants with favorable extraction performance limited essentially to simple amines i.e., compounds with a single amine group and without other functional groups or heterocyclic structures. Much early work was done with expensive reagents, as methyl-di-n-octylamine, but now many inexpensive amines are readily available commercially. Thus, tri-n-octylamine or trifsooctylamine can usually be substituted for methyl-di-n-octylamine in the work described in this paper. Table III indicates the metal ions that have been extracted efficiently with high-molecular-weight amines for the purpose of analytical determinations, purifications or extraction studies. The composition of the aqueous and organic phases before mixing are listed. 
Extraction of Metals With High-Molecular-Weight Amines

\begin{tabular}{|c|c|c|c|}
\hline \multirow{2}{*}{ Metal } & \multicolumn{2}{|c|}{ System } & \multirow{2}{*}{ Reference } \\
\hline & Aqueous Phase & Organic Phase & \\
\hline \multirow{4}{*}{$\begin{array}{l}\text { Actinide(III) } \\
\text { Elements }\end{array}$} & $7-8 \underline{\mathrm{M}} \mathrm{NH}_{4} \mathrm{SCN}$ & $5 \%$ MDOA-xylene & $(44)$ \\
\hline & $\begin{array}{l}5 \mathrm{M} \overline{\mathrm{N}})_{4} \mathrm{SCN} \\
0-0.2 \underline{\mathrm{M}} \mathrm{HCl}--10 \mathrm{M} \mathrm{LICl}\end{array}$ & $\begin{array}{l}10 \% \text { TOA-xylene } \\
20 \% \text { TIOA-xylene }\end{array}$ & $\begin{array}{l}(58) \\
(38)\end{array}$ \\
\hline & $10 \mathrm{M} \mathrm{LiCl}$ & TIA-Amsco $125-82$ & $(56)$ \\
\hline & $10 \underline{\mathrm{MiCl}}$ & THAC-Ams co 125-82 & $(56)$ \\
\hline \multirow[t]{2}{*}{$\mathrm{Ag}(\mathrm{I})$} & Thiosulrate Solution & $\begin{array}{l}\text { Various amines or quatemary ammonium } \\
\text { compounds in methylene chloride }\end{array}$ & (21) \\
\hline & $\begin{array}{l}\text { Various concentrations of } \mathrm{HCl} \text {, } \\
\mathrm{LiCl} \text { and } \mathrm{CsCl}\end{array}$ & $10 \%$ iDOA-trichloroethylene & (4) \\
\hline $\mathrm{Ca}(\mathrm{II}), \mathrm{Mg}(\mathrm{II})$ & $\mathrm{pH}, 12.2-12.9$ & $\begin{array}{l}\text { 8-quinolinol with various quaternary } \\
\text { ammonium salts in methyl isobutyl } \\
\text { ketone }\end{array}$ & (23) \\
\hline \multirow[t]{4}{*}{$\operatorname{Co}(I I)$} & $>6 \underline{\mathrm{M} \mathrm{HCl}}$ & $8 \%$ MDOA-trichloroethylene & $(24)$ \\
\hline & $6-10 \mathrm{HCl}$ & $\begin{array}{l}0.1 \mathrm{M} \text { TOA (or TIOA) in nydrocarbon } \\
\text { diluents }\end{array}$ & (27) \\
\hline & $>6 \underline{\mathrm{MHCl}}$ & TIOA-xylene & $(28,29)$ \\
\hline & $>4 \underline{\mathrm{MHCl}}$ & $\begin{array}{l}\text { Various amines in polar and non- } \\
\text { polar diluents }\end{array}$ & (15) \\
\hline \multirow[t]{2}{*}{$\operatorname{Cr}(\mathrm{VI})$} & Aqueous solution of $\mathrm{H}_{2} \mathrm{CrO}_{4}$ & $5 \%$ MDOA-chloroform & (2) \\
\hline & $\mathrm{H}_{2} \mathrm{Cr}_{2} \mathrm{O}_{7}-6 \mathrm{MHCl}$ & $\begin{array}{l}5 \% \text { TBA-chloroform } \\
5 \% \text { TIOA-xylene }\end{array}$ & $\begin{array}{l}(19) \\
(29)\end{array}$ \\
\hline
\end{tabular}


Table III (ContInued)

\begin{tabular}{|c|c|c|c|}
\hline \multirow{2}{*}{ Metal } & \multicolumn{2}{|c|}{ System } & \multirow{2}{*}{ Reference } \\
\hline & Aqueous Phase & Organic Phase & \\
\hline $\mathrm{Cu}(\mathrm{II})$ & $>4 \underline{\mathrm{M} \mathrm{HCl}}$ & $8 \%$ MDOA-trichloroethylene & (24) \\
\hline \multirow[t]{5}{*}{$\mathrm{Fe}(I I I)$} & $>1 \underline{\mathrm{M}} \mathrm{HCl}$ & $8 \not 6$ MDOA-trichloroethylene & (24) \\
\hline & $>1 \underline{\mathrm{M} \mathrm{HCl}}$ & 5-20\% TIOA-xylene & (29) \\
\hline & $>1 \underline{\mathrm{MHCl}}$ & $\begin{array}{l}\text { Various amines in polar and non- } \\
\text { polar diluents }\end{array}$ & (14) \\
\hline & $1 \underline{\mathrm{M} \mathrm{SO}}{ }_{4}=\mathrm{pH} \mathrm{I}$ & $\begin{array}{l}\text { Various primary amines in hydro- } \\
\text { carbon diluents }\end{array}$ & (3) \\
\hline & $\begin{array}{l}\text { Aqueous slurry of impure slum } \\
\text { crystals }\end{array}$ & 5\% Primene JM-kerosene & (30) \\
\hline \multirow[t]{4}{*}{$\mathrm{HP}(\mathrm{IV})$} & $>8 \underline{\mathrm{M} \mathrm{HCl}}$ & 5\% MDOA (or TIOA) in xylene & $(19,29,44)$ \\
\hline & $\sim 8 \underline{\mathrm{M}} \mathrm{HCl}$ & 0.2 M TOA-cyclohexane & $(45,46)$ \\
\hline & $0.2-2.0 \mathrm{~N} \mathrm{H}_{2} \mathrm{SO}_{4}$ & 5\% MDOA-xylene & (44) \\
\hline & $0.2-2.0 \underline{\mathrm{N}} \mathrm{H}_{2} \mathrm{SO}_{4}$ & $\begin{array}{l}0.1 \text { M TOA (or TIOA) in } 97 \% \text { kerosene- } \\
3 \% \text { tridecanol }\end{array}$ & (27) \\
\hline \multirow[t]{3}{*}{$\begin{array}{l}\text { Lanthanide (III) } \\
\text { Elements }\end{array}$} & $\begin{array}{l}\text { Low } \mathrm{HNO}_{3} \text {, High nitrate salt } \\
\text { conc. }\end{array}$ & $1 \underline{M}$ TOA or TIOA in benzene & $(3,27)$ \\
\hline & 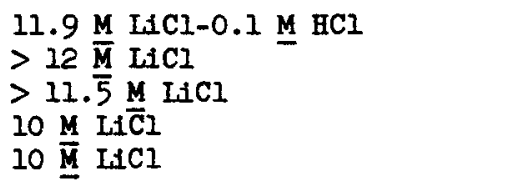 & $\begin{array}{l}20 \% \text { TIOA-methylene chloride } \\
20 \% \text { TIOA-xylene } \\
\text { 40-60\% TIOA-xylene } \\
\text { TIA-Amsco 125-82 } \\
\text { THAC-Amsco } 125-82\end{array}$ & $\begin{array}{l}(38) \\
(38) \\
(38) \\
(56) \\
(56)\end{array}$ \\
\hline & I $\mathrm{M} \mathrm{SO \textrm {H } _ { \mathrm { t } }}=\mathrm{pH} \mathrm{I}$ & $0.1 M$ Primene $J M-T$ in hydrocarbon & (3) \\
\hline
\end{tabular}


$5 \%$ MDOA-xylene

8\% TBA-chloroform (or methylene

$>6 \underline{\mathrm{M} \mathrm{HCl}}$

$5 \%$ TIOA-xylene

$1.5 \mathrm{M} \mathrm{H}_{2} \mathrm{SO}_{4}$

4.0-4.8 $\mathrm{M} \mathrm{H}_{2} \mathrm{SO}_{4}$

$1.85 \mathrm{M} \mathrm{H}_{3} \mathrm{PO}_{4}$

Various $(\mathrm{COOH})_{2}$ solutions

5\% MDOA-trichloroethylene

$8 \%$ TBA-methylene chloride

5\% MDOA-trichiloroethylene

Various concentrations of TBA in chloroform (or methylene chloride)

$\mathrm{Np}(\mathrm{VI})$

$\mathrm{Np}$ (IV)

$\mathrm{Pa}(\mathrm{V})$
1-10 M HNO

Excess fertous sulfamate

Excess ferrous sulfamate in: 2-8 $\mathrm{M} \mathrm{HNO}_{3}$

$2 \mathrm{M} \mathrm{HNO}_{3}$

Dilute $\mathrm{HNO}_{3}$ + nitrate salts

0.1-10 $\mathrm{M} \mathrm{HNO}_{3}$

Excess ferrous sulfamate

2-8 $\mathrm{M} \mathrm{HNO}_{3}$

Excess $\mathrm{NaBrO}_{3}$

1-10 $\mathrm{N} \mathrm{H}_{2} \mathrm{SO}_{4}$

Excess ferrous sulfamate

10\% TOA-xylene

\section{$0.2 \mathrm{M} \mathrm{B}-104-\mathrm{xylene}$}

$0.1,0.3 \mathrm{M}$ TIOA-xylene

$0.1,0.3 \bar{M}$ TIOA-xylene

$0.1 \mathrm{M}$ tetraheptyl ammonium nitrate in $x y$ lene

0.3 M TIOA-xylene

0.001 M Primene JM-T-Amsco 125-82

5\% MDOA-xylene (or chloroform)

4-11 $\mathrm{M} \mathrm{HCl}$ 
Table III (Continued)

\begin{tabular}{|c|c|c|c|}
\hline \multirow{2}{*}{ Metal } & \multicolumn{2}{|c|}{ System } & \multirow{2}{*}{ Reference } \\
\hline & Aqueous Phase & Organic Phase & \\
\hline \multirow{6}{*}{$\begin{array}{l}\mathbf{P e}(\mathrm{v}) \\
\text { (Continued) }\end{array}$} & $4.4 \mathrm{M} \mathrm{HCl}$ & $\begin{array}{l}\text { Various concentrations of TBA in } \\
\text { nitrobenzene }\end{array}$ & $(54)$ \\
\hline & $8 \underline{\mathrm{M} \mathrm{HCl}}$ & 5-30\% Amine IA-I in kerosene & $(16)$ \\
\hline & $1.8 \mathrm{M} \mathrm{H}_{3} \mathrm{PO}_{4}$ & 5\% MDOA-trichlorcethylene & (55) \\
\hline & $6 \mathrm{M} \mathrm{HNO}_{3}$ & $0.5 \underline{M}$ TOA-benzene & (5I) \\
\hline & 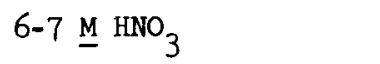 & 10\% TOA-xylene & $(36)$ \\
\hline & $0.5 \mathrm{M} \mathrm{H}_{2} \mathrm{SO}_{4}$ & $5 \%$ MDOA-trichloroethylene & (49) \\
\hline \multirow[t]{2}{*}{$\mathrm{Pb}(\mathrm{II})$} & Thiosulfate solution & $\begin{array}{l}\text { Various amines and substituted } \\
\text { ammonium salts }\left[\mathrm{NH}(\mathrm{Bu})_{3} \mathrm{NO}_{3}\right] \text { in } \\
\text { methylene chloride }\end{array}$ & (2I) \\
\hline & $1.8 \mathrm{M} \mathrm{HCl}$ & $30 \%$ Aliquat 336 in benzene & (22) \\
\hline $\mathrm{Pd}(\mathrm{II})$ & Thiosulfate solution & $\begin{array}{l}\text { Various amines and substituted } \\
\text { ammonium salts }\left[\mathrm{NH}(\mathrm{Bu})_{3} \mathrm{NO}_{3}\right] \text { in } \\
\text { methylene chloride }\end{array}$ & $(21)$ \\
\hline \multirow[t]{2}{*}{ Po(IV) } & $6 \underline{\mathrm{M} \mathrm{HCl}}$ & 5\% TBA-chloroform & (19) \\
\hline & $5 \underline{\mathrm{M}} \mathrm{HCl}-\mathrm{I} \underline{\mathrm{M}} \mathrm{HNO}_{3}$ & 5\% TBA-chloroform & (19) \\
\hline \multirow[t]{3}{*}{$\mathrm{Pu}(\mathrm{IV})$} & 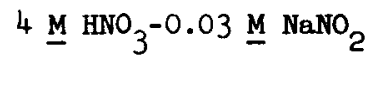 & $\begin{array}{l}0.15 \mathrm{M} \text { TIA-Amsco containing } 2 \% \\
\text { n-octyl alcohol }\end{array}$ & $(60)$ \\
\hline & $8 \mathrm{M} \mathrm{HNO}_{3}$-Excess $\mathrm{NaNO}_{2}$ & $\begin{array}{l}\text { 35\% Amine } 9 \mathrm{D}-178 \text { in Gulf Solvent } \\
\text { BT containing } 10 \% \text { decyl alcohol }\end{array}$ & $(61)$ \\
\hline & $\begin{array}{l}1-12 \mathrm{M} \mathrm{HNO}_{3} \\
0.03-0.05 \underline{\mathrm{K}} \mathrm{NaNO}_{2}\end{array}$ & 10\% TOA-Xylene & $(36)$ \\
\hline
\end{tabular}


1-8 $\mathrm{MNO}_{3}$ Excess $\mathrm{NaNO}_{2}$

Acid deficient $\mathrm{Al}\left(\mathrm{NO}_{3}\right)_{3}$

3-6 $\mathrm{M} \mathrm{HNO}_{3} \cdot$ Excess $\mathrm{NaNO}_{2}$

$3 \mathrm{MNO}_{3}$

2-10 $\mathrm{MHO}_{3}$-Excess $\mathrm{NaNO}_{2}$

Excess $\mathrm{NaNO}_{2}$ in $1-5 \mathrm{~N}_{2} \mathrm{SO}_{4}$ or $1 \underline{\mathrm{N}} \mathrm{H}_{2} \mathrm{SO}_{4}^{2}-4 \underline{\mathrm{N}}\left(\mathrm{NH}_{4}\right)_{2} \mathrm{SO}_{4}$

$\mathrm{Pu}(\mathrm{VI})$

2-8 $\mathrm{M} \mathrm{HNO}_{3}$-Excess $\mathrm{NaBrO}_{3}$

1 M $\mathrm{CH}_{3} \mathrm{COOH}$ $6-9 \mathrm{M} \mathrm{HCl}-0.5 \mathrm{M} \mathrm{HNO}_{3}$
$4.8 \mathrm{M} \mathrm{HCl}$

$\mathrm{Ru}(\mathrm{IV})$

$\mathrm{Ta}(\mathrm{V})$

$\operatorname{Tc}$ (VII)
$0.1-9 \mathrm{M} \mathrm{HCl}$

$>4.8 \mathrm{M} \mathrm{H}_{2} \mathrm{SO}_{4}$

Various concentrations of $(\mathrm{COOH})_{2}$

Acid, neutral, or alkaline solution

$\sim 0.5 \mathrm{M} \mathrm{HNO}, \sim 3 \mathrm{~N}$ total nitrate, Fxcess ferrrous sulfamate

$0.5 \mathrm{M} \mathrm{SO}_{4}=$, pH $0.3-1.4$
$0.1 \mathrm{M}$ B-104-xylene or 0.1 M Aliquat336-xylene

5\% TIOA-xylene

0.5 M TIINA-xylene

$0.01 \mathrm{r}$ TBAN in chloroform-benzene $(1: 1)^{-}$

$10 \%$ TLA-xylene

0.01 M Primene M- $\Gamma$-xylene

0.1 M B-104. xylene

$20 \%$ TIOA-xylene containing $3 \%$ buty 1 Cellosolve

5\% TBA-chloroform

5\% TIOA-xylene

5\% TIOA-xylene

$8 \%$ TBA-methylene chloride

Various concentrations of TBA in chloroform or methylene chloride

Various amines or quaternary anmonium compounds dissolved in cyclohexane or toluene

$0.3 \mathrm{M}$ TLA in Amsco containing 5\% tridecanol 
Table III (Continued)

\begin{tabular}{|c|c|c|c|}
\hline \multirow{2}{*}{ Metal } & \multicolumn{2}{|c|}{ System } & \multirow{2}{*}{ Reference } \\
\hline & Aqueous Phase & Organic Phase & \\
\hline \multirow[t]{5}{*}{$\operatorname{Th}(I V)$} & $1-6 \mathrm{M} \mathrm{HNO}_{3}$ & $\begin{array}{l}0.1-0.4 \mathrm{M} \text { TOA (or TIOA) in benzene } \\
\text { or toluene }\end{array}$ & (13) \\
\hline & $\sim 2.5 \underline{\mathrm{M} \mathrm{Al}}\left(\mathrm{NO}_{3}\right)_{3}, 1.5 \mathrm{M} \mathrm{NH}_{4} \mathrm{OH}$ & 5-20\% TIOA-xylene & (37) \\
\hline & $0.1 \mathrm{M} \mathrm{HCl}-12 \mathrm{M} \mathrm{IiCl}$ & $20 \%$ TIOA-xylene & $(38)$ \\
\hline & $\begin{array}{l}\mathrm{pH} \sim 0.05,120-137 \mathrm{~g} / 1 \mathrm{SO}_{4}= \\
26-33 \mathrm{~g} / 1 \mathrm{PO}_{4} \equiv\end{array}$ & $\begin{array}{l}0.1 \mathrm{M} \text { Primene } \mathrm{JM} \text { in kerosene con- } \\
\text { taining } 3 \% \text { tridecanol. }\end{array}$ & (39) \\
\hline & $\begin{array}{l}\text { Various aqueous solutions of } \\
\mathrm{HCl}, \mathrm{HNO}_{3} \text {, } \mathrm{H}_{3} \mathrm{PO}_{4} \text { or } \mathrm{H}_{2} \mathrm{SO}_{4} \\
\text { adjusted to acld deficient with } \\
\mathrm{Al}\left(\mathrm{NO}_{3}\right)_{3}\end{array}$ & 5\% TIOA-xylene & (42) \\
\hline \multirow[t]{2}{*}{$\mathrm{v}(\mathrm{V})$} & $1 \mathrm{M}_{4} \mathrm{SO}_{4}=\mathrm{pH} 2$ & $\begin{array}{l}\text { Various primary, secondary or ter- } \\
\text { tiary amines ( } 0.1 \mathrm{M}) \text { in aromatic } \\
\text { hydrocarbon diluents }\end{array}$ & (3) \\
\hline & Thiosulfate solution & $\begin{array}{l}\text { Various amines and substituted } \\
\text { ammonium salts }\left[\mathrm{NH}(\mathrm{Bu})_{3} \mathrm{NO}_{3} \text { ) in }\right. \\
\text { methylene chloride }\end{array}$ & (21) \\
\hline \multirow[t]{4}{*}{$\mathrm{U}(\mathrm{VI})$} & $>6 \mathrm{M} \mathrm{HNO}_{3}$ or nitrate salts & 0.1 M TOA-Amsco D-95 & (3) \\
\hline & $6 \mathrm{M}_{2} \mathrm{HNO}_{3}$ & 10\% TOA-xylene & (36) \\
\hline & $7 \underline{\mathrm{MNO}} 3$ & 5\% MDOA-xylene & (19) \\
\hline & $\begin{array}{l}\mathrm{HNO}_{3}+\mathrm{NH}_{4} \mathrm{NO}_{3}=7 \mathrm{M} \\
\text { Tetrabutylammonium } \\
\text { nitrate }\end{array}$ & Chloroform & (69) \\
\hline
\end{tabular}

$\left(\mathrm{C}_{4} \mathrm{H}_{9}\right)_{4} \mathrm{~N} \cdot \mathrm{NO}_{3}, 25 \mathrm{mg} / \mathrm{mI}$ 
Acld deficient $\mathrm{Al}\left(\mathrm{NO}_{3}\right)_{3}$ solution containing tetrapropylammonium nitrate $(0.1 \%)$

$\sim 2.5 \underline{\mathrm{M} \mathrm{Al}}\left(\mathrm{NO}_{3}\right)_{3}, 1.5 \mathrm{M} \mathrm{NH}_{4} \mathrm{OH}$ U(IV) $0.5-1 \mathrm{M} \mathrm{SO}_{4}=\mathrm{pH} \mathrm{I}$

$\mathrm{U}(\mathrm{VI})$

Sulfate leach liquors $\mathrm{pH} 1-2,0.5-1 \mathrm{M} \mathrm{SO}_{4}=$

$$
0.1-1 \mathrm{M} \mathrm{H}_{2} \mathrm{SO}_{4}
$$

$\mathrm{pH} 1, \sim 1 \mathrm{M} \mathrm{SO}_{4}=$

$\mathrm{pH} 1.5, \sim 0.4 \mathrm{M} \mathrm{sO}_{4}=$

$U(I V)$
$U(V I)$

$\mathrm{U}(\mathrm{VI})$
$>8 \mathrm{M} \mathrm{HCl}$

4-10 $\mathrm{M} \mathrm{HCl}$

2-10 M HCl

3-12 $\underline{\mathrm{M} \mathrm{HCl}}$

$>1 \mathrm{M} \mathrm{HCl}$

$4 \mathrm{M} \mathrm{HCl}$

4-IO $\mathrm{M} \mathrm{HCl}$

$0.5-2 \mathrm{M} \mathrm{CH}_{3} \mathrm{COOH}$ or $0.1 \mathrm{MNO}_{3}-\mathrm{I} \mathrm{MCH}_{3} \mathrm{COOH}$

\section{5-20\% TIOA-xylene}

Various primary or secondary amines $(0.1 \mathrm{M})$ in kerosene or aromatic hydrocarbon diluents

Various secondary or tertiary amines $(0.1 \mathrm{M})$ in kerosene or aromatic hydrocarbon diluents

\section{5\% MDOA-xylene}

0.05 NN NBA-kerosene

$(3,78,79$, 80,83 , $84)$

Various amines $(10 \%)$ in kerosene

5\% Amine 9D-178-toluene $10 \%$ Amine 9D-178-toluene

5-20\% TIOA in xylene or methyl isobutyl ketone

5-30\% Amine LA-1-kerosene

$5 \%$ MDOA-xylene

5\% TIOA-xylene

0.1 M TOA-Amsco D-95

5-20\% TIOA, TLA, or Amine 9D-178 in xylene or methyl isobutyl ketone 
Table III (Continued)

\begin{tabular}{|c|c|c|c|}
\hline \multirow{2}{*}{ Metal } & \multicolumn{2}{|c|}{ System } & \multirow{2}{*}{ Reference } \\
\hline & Aqueous Phase & Organic Phase & \\
\hline \multirow{11}{*}{$\begin{array}{l}U(\mathrm{VI}) \\
\text { (Continued) }\end{array}$} & $2 \mathrm{M} \mathrm{CH}_{3} \mathrm{COOH}$ & $5 \%$ MDOA-Xylene & (19) \\
\hline & $0.1-5 \mathrm{M} \mathrm{CH}_{3} \mathrm{COOH}$ & 0.1 M TOA-Amsco D-95 & (3) \\
\hline & $1-2 \underline{M} \mathrm{HF}$ & 5\% MDOA-xylene & (19) \\
\hline & $\begin{array}{l}\text { Fluoride Salt Solutions } \\
\text { l-5 } \mathrm{M} \mathrm{F}^{-}, \mathrm{pH} \sim 1\end{array}$ & 0.1 M TOA-Amsco D-95 & (3) \\
\hline & $1-2 \underline{M F}$ & $\begin{array}{l}\text { 10\% Amine 9D-178-toluene (saturated } \\
\text { with HF) }\end{array}$ & (87) \\
\hline & Thiosulfate solution & $\begin{array}{l}\text { Various amines or substituted. } \\
\text { ammonium salts in methylene } \\
\text { chloride }\end{array}$ & (21) \\
\hline & $\begin{array}{l}\text { Dilute solutions of oxalic, } \\
\text { formic, or maleic acids }\end{array}$ & $5 \%$ WDOA-xylene & (19) \\
\hline & $\sim 0.3 \mathrm{M} \mathrm{H}_{3} \mathrm{PO}_{4}$ & $5 \%$ MDOA-xylene & (19) \\
\hline & $0.1-\sim 1 \mathrm{MH}_{3} \mathrm{PO}_{4}$ & $0.1 \mathrm{M}$ TOA-Amsco D-95 & (3) \\
\hline & $\begin{array}{l}1 \mathrm{M} \mathrm{Na}_{2} \mathrm{CO}_{3} \\
10-12.3\end{array}$ and/or I $-\mathrm{M} \mathrm{NaHCO}_{3}$ & $\begin{array}{l}\text { Methyl isobutyl ketone containing } \\
0.3 \mathrm{M} 8 \text {-quinolinol and } 0.1 \mathrm{M} \\
\text { Arquad } 2 \mathrm{C}\end{array}$ & (88) \\
\hline & $0.5 \mathrm{M} \mathrm{Na}_{2} \mathrm{CO}_{3}, \mathrm{pH} 10.7$ & $10 \% \mathrm{~B}-104$ in Amsco-G & (31) \\
\hline$Y(I I I)$ & $7-8 \underline{\mathrm{M}} \mathrm{NH}_{4} \mathrm{SCN}$ & 5\% MDOA-xylene & (44) \\
\hline $\operatorname{Zn}(I I)$ & $>1 \underline{\mathrm{M} \mathrm{HCl}}$ & $\begin{array}{l}8 \% \text { MDOA in trichloroethylene, xylene } \\
\text { or chlorcform }\end{array}$ & $(24,29)$ \\
\hline
\end{tabular}


Various concentrations of $\mathrm{HCl}$, $\mathrm{LiCl}$ and $\mathrm{CsCl}$

$\mathrm{Zr}(\mathrm{IV})$

$$
>8 \underline{\mathrm{MHCl}}
$$

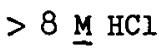$$
0.2-2 \mathrm{~N} \mathrm{H}_{2} \mathrm{SO}_{4}
$$$$
0.2-2 \stackrel{\mathrm{N}_{2} \mathrm{SO}_{4}}{ }
$$

$8 \mathrm{MNO}_{3}$
10\% MDOA-trichloroethylene

5\% MDOA (or TIOA) in xylene

$(19,29,44)$

0.2 M TOA-cyclohexane

5\% MDOA-xylene

$0.1 \mathrm{M}$ TOA (or TIOA) in kerosene contäining $3 \%$ tridecanol

$0.35 \mathrm{M}$ TIA-toluene $0.32 \mathrm{~V}$ Primene $\mathrm{M}-\mathrm{T}$ - toluene

Amine $9 \mathrm{D}-178^{f}-$ mixture of secondary amines

$M D O A^{a}$ - methyl-di-n-octylamine

TOA ${ }^{\mathrm{b}}$ - tri-n-octylamine

TIOA ${ }^{\mathrm{b}}$ - trilsooctylamine

TLAc, d,e - tri-n-laurylamine

THACe - n-tetraheptyl ammonium chloride

TBA ${ }^{e}$ - tri-n-benzylamine

Primene JMf - mixture of primary amines

Primene $J M-\mathrm{T}^{\mathrm{f}}$ - mixture of primary amines

B-104f - isopropanol solution of didodecenyldimethyl-ammonium chloride

Aliquat-336 - mixed trioctyl and tridecyl methyl

TINA ${ }^{\mathrm{h}}$ - trijsononylamine

Amine 2lF81b - I(3-ethylpentyl)-4-ethyloctylamine

Amine $I A-1^{f}$ - secondary amine

NBA - n-benzyl-1-(3-ethyl. pentyl)-4-ethoxyoctylamine

Arquad $2 \mathrm{C}^{\mathrm{c}}-\mathrm{R}_{2} \mathrm{~N}\left(\mathrm{CH}_{3}\right)_{2} \mathrm{Cl}$, where $\mathrm{R}$ averages about a 16 carbon chain ( $75 \%$ in isopropanol)

TBAN - tetrabutylammonium nitrate

\section{Availability}

a - Edcan Laboratories, S. Norwalk, Conn.

b - Union Carbide Chemicals Company, New York 17, N. Y.

c - Armour Chemical Company, 1355 West 3lst Street, Chicago 9, Illinois.

d - Archer-Dantels-Midland Co., Minneapolis 2, Minn.

e - Eastman Kodak Co., Rochester, N. Y.

$f$ - Rohm and Haas Co., Philadelphia 5, Pa.

G - General Mills Company, Minneapolis 13, Minnesota.

h - Heavy Organic Chemicals Ltd., Billingham, England

Amsco Diluents - American Mineral Spirits Co., 1194 Allene Avenue, S.W., Atlanta 9, Georgia 


\section{Silver, Palladium, Lead}

Ziegler ${ }^{(21)}$ has found that the thiosulfate complexes of silver, palladium and lead can be extracted quantitatively from aqueous solutions with organic solutions of various amines or substituted ammonium salts (e.g., $\left.\mathrm{NH}\left(\mathrm{C}_{4} \mathrm{H}_{9}\right)_{3} \mathrm{NO}_{3}, \quad \mathrm{NH}\left(\mathrm{C}_{4} \mathrm{H}_{9}\right)_{3} \mathrm{C}_{2} \mathrm{H}_{3} \mathrm{O}_{2}\right)$. Methylene chloride, chloroform and amyl alcohol were satisfactory diluents.

Schindewolf ${ }^{(4)}$ used $10 \%$ methyl-di-n-octylamine - trichloroethylene to extract silver tracer from various aqueous solutions of hydrochloric acid, lithium chloride and cesium chloride in physico-chemical studies.

The quantitative extraction of lead from aqueous solutions of $1.8 \mathrm{M}$ hydrochloric acid with the quaternary amine, Aliquat 336, in benzene has been described by Petrow and co-workers. (22) They found this technique gave excellent separations of lead from radium and was considerably faster than the anion exchange resin technique previously used.

\section{Calcium and Magnesium}

A method recently has been developed by Katekaru and Freiser ${ }^{(23)}$ for the solvent extraction of calcium at $\mathrm{pH} 12.2-12.9$ and its subsequent spectrophotometric determination using 8-quinolinol in the presence of various quaternary ammonium salts and methyl isobutyl ketone as the organic solvent. A prior extraction of magnesium with the same reagent at a lower $\mathrm{pH}$ and masking of iron with cyanide was employed to eliminate these interferences.

\section{Polonium}

Polonium-210 tracer has been extracted essentially quantitatively (>99\%) from 6 M hydrochloric acid solution with $5 \%$ tri-n-benzylaminechloroform. (19) The extraction from 5 M hydrochloric acid - I M nitric acid and from $6 \underline{\mathrm{M}}$ nitric acid was found to be $93 \%$ and $<10 \%$, respectively.

\section{Zinc, Iron, Copper, Chromium and Cobalt}

The tertiary amines, methyl-di-n-octylamine and tribenzylamine, have been found to be efficient extractants for zinc in hydrochloric acid solutions. (24) Methyl-di-n-octylamine, $8 \%$ in trichloroethylene (or xylene) 


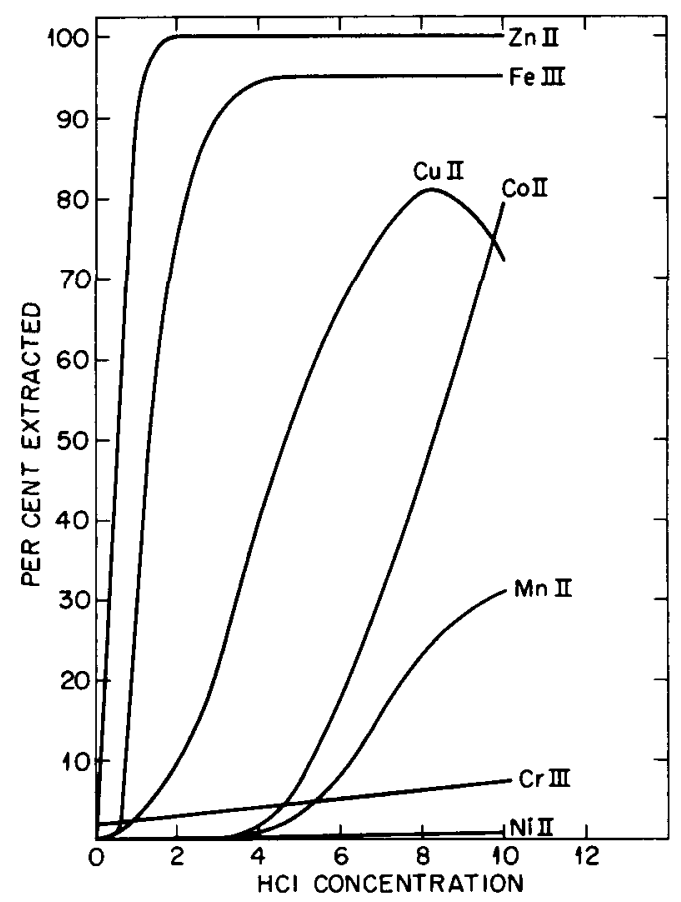

Fig. 1 Extraction of various elements from hydrochloric acid solution with $8 \%$ MDOA-trichloroethylene.

extracts zinc essentially quantitatively from solutions of greater than $2 \underline{M}$ hydrochloric acid. Using chloroform as a diluent reduces the extraction to $77 \%$. The behavior of some of the tracers of the first transition series is shown in Figure 1 (taken from data of Mahiman, Leddicotte, and Moore ${ }^{(24)}$ and Hicks $\left.{ }^{(25)}\right)$. From this figure it is apparent that, in the range 2-3 $M$ hydrochloric acid, zinc can be seperated essentially quantitatively in a single extraction from manganese, cobalt and nickel. Small amounts of copper and chromium extracting may be minimized by appropriate scrubbing of the organic phase. Iron(III) constitutes a major interference and should be removed previously or rendered inextractable by reduction to the ferrous oxidation state. The high extractability of zinc from dilute hydrochloric acid solution provides a rapid separation from alkalies, alkaline earths, lanthanides, actinides, zirconium, hafnium, niobium, tantalum, manganese, cobalt,nickel, copper, chromium and other elements which do not form extractable anionic species under the conditions used. 
The extraction of zinc from dilute hydrochloric acid solution with methyl-di-n-octylamine or trilsooctylamine dissolved in methyl isobutyl ketone has been reported by Scroggie and Dean. (26) They developed a procedure for the colorimetric determination of $z$ inc in the organic phase using the Zincon reagent (2-carboxy-2'hydroxy-5'-sulfoformazylbenzene).

Schindewolf ${ }^{(4)}$ has studied extensively the physico-chemical variables involved in the extraction of zinc from aqueous solutions of hydrochloric acid, cesium chloride and lithium chloride with "liquid anion exchangers" and compared the results with conventional solid anion resin exchangers. He used the system, $10 \%$ methyl-di-n-octylamine-trichloroethylene, and postulated the extractable complex to be $(\mathrm{RH})_{2} \mathrm{ZnCl}_{4}$, where $\mathrm{R}$ represents the substituted ammonium ion.

Applications of the technique have also proved valuable for the separation of cobalt from nickel at higher concentrations of hydrochloric acid. In a brief survey, ${ }^{(27)}$ the extraction of cobalt with $0.1 \mathrm{M}$ solutions of the tertiary amines, tri-n-octylamine and triisooctylamine, in various hydrocarbon diluents was significant from 6-10 $\underline{M}$ hydrochloric acid solution but not from nitric or sulfuric acid solutions. In general, the extraction of ccbalt from hydrochloric acid solution by secondary amines was very low (3-10\%) and less than $0.5 \%$ with primary amines. N1ckel extractions were too low to be measured in all cases. The Bureau of Mines has demonstrated a successful process ${ }^{(28)}$ for separating cobalt and nickel in the hydrochloric acid-trilsooctylamine-xylene system.

The extraction of chromic acid from aqueous solution with $5 \%$ methyldi-n-octylamine-chloroform has been effected by Smith and Page. (2) Dichromic acid has been observed to extract from hydrochloric acid solutions with $5 \%$ tri-n-benzyl-amine-chloroform ${ }^{(19)}$ and $5 \%$ triisooctylamine-xylene (29) with soparation from plutonium, uranium and some other elements indicated. Good and Bryan, in a series of papers, have raported on the extraction mechanism and nature of the extracted species of 1 ron(III) ${ }^{(14)}$ and cobalt(II) (15) in hydrochloric acid-amine systems. 
Efficient extraction of ferric iron from sulfate solutions has been reported $(3)$ by using primary amines dissolved in various hydrocarbon diluents. Extraction coefficients of 40 were found with primary amines, <0.5 with secondary and $<0.01$ with tertiary amines from aqueous solutions of $1 \underline{M}$ sulfate, $\mathrm{pH} 1,1 \mathrm{~g} / \mathrm{IFe}$ (III) and a phase ratio of 1 . $\mathrm{Fe}(\mathrm{II})$ does not extract appreciably in any case.

An interesting application of the amine extraction technique in the recent development ${ }^{(30)}$ of a method for the purification of alum crystals obtained from the leaching of sulphated shale. A $5 \%$ solution of the primary amine, Primene $\mathrm{JM}$, in kerosene essentially completely removed the iron impurity with a negligible loss of aluminum. Countercurrent liquidIlquid extruction tests indicated that reagent costs were low and the process was found to be an attractive alternative to recrystallization.

\section{Molybdenum}

The extraction behavior of molybdenum is very similar to that of uranium in amine systems. Thus, in the Amex process, ${ }^{3)}$ molybdenum extracts with uranium. Chloride stripping can be used to strip the uranium from the amine extractant after which molybdenum can be stripped with an alkaline solution like sodium carbonate. In a typical case ${ }^{(31)}$ when a $0.1 \underline{\mathrm{M}}$ solution of amine 9D-178 in kerosene, loaded to $1.9 \mathrm{~g} / \mathrm{l}$ uranium and $2.3 \mathrm{~g} / \mathrm{l}$ molybdenum, was contacted with a $0.9 \underline{\mathrm{M}}$ sodium chloride-0.1 $\mathrm{M}$ hydrochloric acid stripping solution ( $\frac{\text { Organic }}{\text { Aqueous }}=2$ ), $99 \%$ of the uranium and only $2 \%$ of the molybdenum stripped from the organic phese. The extraction coeff1cient of molybdenum decreases as its concentration decreases.

\section{Ruthenium}

In the system, hydrochloric acid - $5 \%$ triisooctylamine-xylene, ruthenium(IV) has been found to extract efficiently from dilute hydrochloric acid with decreasing extractability at increasing hydrochloric acid concentration $^{(29)}$ (Table IV).

The extraction of nitrosyl ruthenium nitrates by trilaurylamine and di(tridecyl)amine in toluene has been described recently. (43) Increasing 
Table IV

Extraction of Fission Products from Hydrochloric Acid With 5\% Triisooctylamine-Xylene

\begin{tabular}{|c|c|c|c|c|c|}
\hline Element & $\mathrm{HCl}, \mathrm{M}$ & $\begin{array}{c}\text { Tracer } \\
\text { Extracted, } \%\end{array}$ & Element & $\mathrm{HCl}, \underline{\mathrm{M}}$ & $\begin{array}{c}\text { Tracer } \\
\text { Extracted, } \%\end{array}$ \\
\hline \multirow[t]{9}{*}{$\mathrm{ND}-95$} & 2.2 & 0.3 & $\mathrm{Zr}-95$ & 2,1 & 0.02 \\
\hline & 4.4 & 3.1 & & 4.2 & 0.4 \\
\hline & 4.6 & 6.2 & & 6.3 & 0.7 \\
\hline & 4.8 & 9.5 & & 8.4 & $8 y .6$ \\
\hline & 5.0 & 17.4 & & 10.5 & 99.0 \\
\hline & 6.5 & 90.2 & & & \\
\hline & 6.8 & 96.8 & Eu-152-154 & 2.2 & $<0.01$ \\
\hline & 9.0 & 99.2 & & 4,3 & $<0.01$ \\
\hline & & & & 6.5 & $<0.02$ \\
\hline \multirow[t]{8}{*}{$R u-106$} & 0.1 & 82.3 & & 8.7 & $<0.03$ \\
\hline & 0.2 & 77.7 & & 10.9 & 0.05 \\
\hline & 1.1 & 75.0 & & & \\
\hline & 2.1 & 74.3 & $\mathrm{Sr}-85$ & 2.1 & 0 \\
\hline & 4.2 & 72.5 & & 4.2 & 0 \\
\hline & 6.4 & 69.8 & & 6.4 & 0 \\
\hline & 8.5 & 58.6 & & 8.5 & 0 \\
\hline & 10.6 & 29.4 & & 10.6 & 0 \\
\hline
\end{tabular}

extraction of ruthenium with decreasing acidity was observed over the range $8 \underline{N}$ nitric acid to $2 \underline{N}$ nitric acid $+4 \underline{N}$ sodium nitrate $\left(E_{a}^{0}=0.015,0.13\right.$, respectively) in the system, trilaurylamine-toluene. Equilibrium was not attained in 95 hours.

7. Technetium

A process $(32)$ has been develoycd for the extraction of technetium(VII), uranium(VI), and neptunium(IV) from nitric acid solutions of fluorination plant residues using $0.3 \mathrm{M}$ trilaurylamine dissolved in Amsco containing 5\% tridecanol. The technetium was stripped from the organic phase with 
I N ammonium hydroxide, after removal of the uranium and neptunium with $0.5 \underline{N}$ nitric acia and $0.1 \underline{N}$ sulfuric acid, respectively.

The extraction of technetium(VII) with several organo-nitrogen compounds has been reported recently by Boyd and Larson (33) who found the extraction mechanism was anion exchange. The magnitude of $\mathrm{E}_{\mathrm{a}}^{\circ}$ for extraction from acid solutions increased in the order primary $<$ secondary $<$ tertiary amine solutions in cyclohexane. Among the tertiary amines a decrease in basicity was accompanied by decreased extraction coefficients. Quaternary ammonium salts dissolved in inert diluents gave efficient extractions not only from acid but also from neutral and alkaline solutions.

\section{Titanium}

The extraction of titanium(IV) from sulfate solution has been found $(34)$ to be low with straight-chain secondary amines and lower still with the highly-branched secondary and symetrical tertiary amines. However, efficlent extraction is possible with various primary amines. These variations in extraction are qualitatively similar to those obtained with other tetravalent metal ions. The extraction of titanium(IV) was found to decrease with increasing sulfate concentration and to increase with increasing pH. From aqueous solutions of $0.25 \mathrm{~g} / \mathrm{l}$ titanium(IV), $0.5 \mathrm{M}$ sulfate, and $\mathrm{pH}$ range $0.3-$ 1.4, extraction coefficients were found to be greater than 50 with the primary amine, $0.1 \mathrm{M}$ Amine 21F81, in kerosene.

\section{Vanadium}

Under appropriate conditions, primary, secondary, and tertlary amines extract vanadium(V) from sulfate solutions. $(3,35)$ Vanadium(IV) was not extracted appreciably, but vanadium $(V)$ extracted well $\left(\mathrm{E}_{\mathrm{a}}^{\circ} \sim 20\right)$ in the $\mathrm{pH}$ range 1.8-2.5 at extractant loadings of $5 \mathrm{~g} / 1$ vanadium. The extraction coefficient was observed to decrease as the metal concentration decreased. Stripping was accomplished readily with alkaline solutions.

Ziegler ${ }^{(21)}$ has found that a vanadyl-thiosulfate complex can be extracted with various amines and substituted ammonium salts dissolved in organic solvents. 


\section{Thorium}

a. Nitric Acid Solution

The extraction of an anionic thorium complex, $\operatorname{Th}\left(\mathrm{NO}_{3}\right)_{6}^{2-}$, from nitric acid solutions with tri-n-octylamine and triisooctylamine dissolved in benzene or toluene has been described by Carswell and Lawrance. (13)

Using the system, tri-n-octylamine-xylene, Keder, Sheppard and Wilson found the extraction of thorium from nitric acid solutions to be slightly less than that of uranium(IV) and considerably less than that of neptunium(IV) and plutonium(IV). Highest extraction coefficients $\left(E_{a}^{\circ}\right)$ for thorium were found to be about 0.5 at intermediate nitric acid concentrations.

The efficient extraction of thorium from acid-deficient aluminum nitrate solutions with triisooctylamine-xylene has been reported by Schults and coworkers. (37)

\section{b. Hydrochloric Acid Solution}

It is well-known that thorium does not form anionic chloro species appreciably even in concentrated hydrochloric acid solution. The inextractability of thorium from hydrochloric acid solution with triisooctylaminexylene is shown in Table V. ${ }^{(29)}$ However, recently it has been demonstrated (38) that thorium exhibits extraction coefficients greater than $I$ in the system, 12 M lithium chloride - 0.1 M hydrochloric acid - $20 \%$ trilsooctylamine-xylene.

\section{c. Sulfuric Acid Solution}

Crouse and Brown (39) have reported that the thorium extraction power of amines in sulfate media is strongly dependent on the amine type and structure. Primary amines were found to have tremendous affinity and tertiary amines negligible affinity for thorium. Performance of the secondary amines was found to be intermediate and to vary greatly with the structure of the alkyl chains. Using the primary amine, $0.1 \mathrm{M}$ Primene JM in $97 \%$ kerosene-3\% tridecanol, they found an extraction coefficient of 400 even at near maximum loading of the solvent $(2.8 \mathrm{~g} / 1$ thorium $)$. These amines have much lower affinity for uranium, lanthanides, iron and many other elements, so that a great degree of selectivity can be achieved for the extraction of 
thorium. The extraction of lanthanides is minimized by operating with an organic phase containing high concentrations of thorium. The thorium can be stripped from the primary amine with sodium hydroxide, sodium carbonate, or various salts and acids.

Table V

Extraction of Thorium-230 (Ionium) Tracer

From Hydrochloric Acid With $5 \%$

Triisooctylamine-Xylene

\begin{tabular}{lc}
\hline $\mathrm{HCI}, \underline{\mathrm{M}}$ & $\operatorname{Th}^{230}$ Extracted, \% \\
\hline 2.2 & 0.003 \\
4.5 & 0.005 \\
6.7 & 0.010 \\
8.9 & 0.016 \\
11.1 & 0.020
\end{tabular}

Studies of the systems, Primene JM-T-thorium sulfate ${ }^{(40)}$ and di(tridecyl)amine-thorium sulfate ${ }^{(41)}$ have been reported.

Wilson (42) has studied the extraction behavior of thorium in several acid and acid-deficient systems with trilsooctylamine-xylene and developed a procedure for the determination of thorium. He found that thorium could be extracted quantitatively from aqueous solutions of $10 \mathrm{~N}$ sulfuric acid, $12 \underline{M}$ hydrochloric acid, $6 \underline{\mathrm{M}}$ nitric acid-6 $\underline{\mathrm{M}}$ hydrochloric acid, $5 \underline{\mathrm{N}}$ phosphoric acid (containing enough nitric acid to solubilize the thorium), and $14 M$ nitric acid.

\section{Zirconium and Hafnium}

\section{a. Nitric Acid Solution}

$\Lambda$ recent progress report ${ }^{(43)}$ described preliminary work on the extraction of zirconium by trilaurylamine and Priment JM-T in toluene and Amsco. High extractability of zirconium was observed from intermediate to high concentrations of nitric acid. 


\section{b. Hydrochloric Acid Solution}

The extraction of zirconium-95 and hafnium-181 tracers from hydrochloric acid solutions with $5 \%$ methyl-di-n-octylamine-xylene has been demonstrated. (19, The extraction behavior was similar with zirconium being preferentially extracted. Extractions of the zirconium and hafnium tracers were essentially quantitative in the range $11-12 \mathrm{M}$ hydrochloric acid.

Zirconium-95 tracer has also been extracted efficiently from high concentrations of hydroshloric acid with $5 \%$ triisooctylamine-xylene. (29)

Cerrai and Testa $(45,46)$ investigated a series of primary, secondary, and tertiary amines as extractants for zirconium and hafnium in hydrochloric acid media. Under similar aqueous phase conditions, the selectivity was in the order tertiary $>$ secondary $>$ primary amines. By lowering the temperature of extraction and adding small amounts of nitric acid to the hydrochloric acid system, the separaticn factor for zirconium and hafnium could be increased but yields were decreased. Tri-n-octylamine was found to be a good extractant for the zirconium-hafnium fractionation. Profitable applications in multi-stage counter-current processes are indicated.

Feldman and Pritchard ${ }^{(47)}$ have used $20 \%$ triisooctylamine-xylene to remove zirconiun from zirconium metal alloys prior to the spectrographic determination of titanium and magnesium.

\section{c. Sulfuric Acid Solution}

High extractions of zirconium and hafnium from dilute sulfuric acid solution have been effected with the tertiary amines, methyl-di-n-octylaminexylene ${ }^{(44)}$ and tri-n-octylamine or triisooctylamine in inert diluents. (27) $0.1 \mathrm{M}$ tri-n-octylamine in $97 \%$ kerosene-3\% tridecanol gave greater than $99 \%$ extruction of zirconium and $90 \%$ extraction of hafnium from $I$ M sulfuric acid solution. Separation factors of zirconium over hafnium of the order of 10 or more were found.

\section{Niobium and Tantalum}

a. Hydrochloric Acla Solution

Methyl-di-n-octylamine-xylene solutions have been used ${ }^{(48)}$ to 
separate niobium-95 and tantalum-182 tracers in hydrochloric acid solutions. Niobium-95 tracer extracted essentially quantitatively from strong hyarochloric acid solution, while the extraction of tantalum-182 tracer was very low at all concentrations of hydrochloric acid. In a typical experiment (Tables VI, VII), aqueous hydrochloric acid solutions were extracted for five minutes with equal volume portions of $5 \%$ methyl-di-n-octylamine-xylene.

Table VI

The Effect of Hydrochloric Acid Concentration On the Extraction of $\mathrm{Mb} 95$ With $5 \%$ Methyl-di-n-octylamine in Xylene

\begin{tabular}{cc}
\hline $\mathrm{HCl}, \underline{\mathrm{M}}$ & No95 \\
\hline 2 & 4.0 \\
3 & 2.4 \\
4 & 2.2 \\
6 & 21.5 \\
8 & 99.3 \\
9.6 & 100.0 \\
(Control) 9.6 (no MDOA) & 0.04
\end{tabular}

Table VII

The Effect of $\mathrm{HCl}$ Concentration on the Extraction of Tal82 with $5 \%$ Methyldi-n-octylamine in Xylene

\begin{tabular}{lc}
\hline HCl, M & Ta $^{182}$ Extracted, \% \\
\hline 2.9 & 0.3 \\
4.9 & 0.1 \\
7.3 & 0.6 \\
8.9 & 1.1 \\
10.1 & 1.4 \\
11.2 & 1.4
\end{tabular}

Similarly, niobium and tantalum separations at one milligram per milliliter were effected. The niobium in the organic phase could be stripped readily with nitric acid, dilute hydrochloric acld and intermediate concentrations of sulfuric acid solutions. 
Essentially quantitative separations of niobium from tantalum have been effected $(50)$ by extracting for 5 minutes the niobium from 11 M hydrochloric acid solution with $8 \%$ tri-n-benzylamine in chloroform or methylene chloride. The extraction coefficients found for niobium and tantalum using chloroform as solvent were 74.38 and 0.002 , respectively. Using methylene chloride as solvent for the tri-n-benzylamine, the extraction coefficients for niobium and tantalum were 80.5 and 0.0023 , respectively.

High extractability of niobium-95 tracer from intermediate to high concentrations of hydrochloric acid has been demonstrated with $5 \%$ trilsooctylamine-xylene (29) (Table IV).

\section{b. Sulfuric Acid Solution}

Niobium-95 tracer has been found to extract approximately 50\% from 1.5 M sulfuric acid solution with an equal volume portion of $5 \%$ methyl-di-noctylamine-trichloroethylene. (49)

The extraction of niobium and tantalum from sulfuric acid solution using $8 \%$ tri-n-benzylamine-methylene chloride has been reported. (50) Although essentially quantitative separations of the two elements have been demonstrated at $4.5 \mathrm{M}$ sulfuric acid solution (niobium preferentially extracts), the concentration of sulfuric acid is quite critical and limits the utility of the separation. Tantalum extracts at higher concentrations of sulfuric acid.

\section{c. Phosphoric Acid Solution}

Niobium-95 tracer has been found to exhibit 75\% extraction from 1.85 M phosphoric acid solution with an equal volume portion of $5 \%$ methyl-di-noctylamine-trichloroethylene. (49)

\section{d. Oxalic Acid Solution}

Favorable extractions of niobium and tantalum oxalate species were found $(50)$ with tri-n-benzylamine dissolved in chloroform or methylene chloride. No extraction was found with tri-n-benzylamine dissolved in benzene. toluene, xylene, or carbon tetrachloride. 


\section{Protactinium}

\section{a. Nitric Acid Solution}

The extraction coefficient of protactinium tracer from nitric acid solutions with tri-n-octylamine in benzene ${ }^{(51)}$ and xylene ${ }^{(36)}$ was found to be greatest at intermediate nitric acid concentrations, but less than I in all cases.

Protactinium(V) has been reported $(16)$ to exhibit very low extractability from nitric acid solutions with the secondary amine, Amberlite LA- 1 , in kerosene.

\section{b. Hydrochloric Acid Solution}

Inasmuch as protactinium forms anionic chloro species in hydrochloric acid solutions, several amine systems have been used to extract these complexes. Solutions of $5 \%$ methyl-di-n-octylamine in xylene or chloroform have been shown ${ }^{(52)}$ to effect high extractions of protactinium tracer from $6 \underline{M}$ hydrochloric acid solution. The extraction of protactinium-233 tracer from aqueous hydrochloric acid solutions with equal volume portions of $5 \%$ methyl-di-n-octylamine-xylene ${ }^{(19)}$ using five minute extraction periods is shown in Table VIII.

Table VIII

Extraction of Protactinium-233 Tracer From Hydrochloric Acid Solutions With 5\% MDOA-Xylene

\begin{tabular}{cc}
\hline $\mathrm{HCl}, \mathrm{M}$ & $\mathrm{Pa} 233$ Tracer Extracted, $\%$ \\
\hline 2.0 & 16.6 \\
4.0 & 77.0 \\
6.0 & 98.0 \\
8.0 & 99.1 \\
10.1 & 99.3 \\
11.1 & 99.0
\end{tabular}

The extraction behavior of protactinium tracer in the hydrochloric acidtrifsooctylamine-xylene system has been found to be similar to that of uranium(VI). (29) Thus, at intermediate hydrochloric acid concentrations, 
one may effect an excellent separation of protactinium from thorium, alkalies, alkaline earths, ruthenium, lanthanides, zirconium, hafnium, niobium, tantalum, plutonium(III,IV), americium, curium, and many other elements which do not form extractable anionic species under these conditions.

Goble and Maddock (53) studied the extraction coefficients for protactinium. 233 tracer by $5 \%$ tri-n-butyl amine in various solvents from $5 \underline{M}$ hydrochloric acid solution as a function of the dielectric constant of the pure bulk diluent. They noted an increase in extracting power with dielectric constant and base strength of the diluent.

Casey and Maddock ${ }^{(54)}$ studied the variation of the extraction coefficient for protactinium-233 tracer with the concentration of tri-n-benzylamine dissolved in nitrobenzene.

The extraction of protactinium-233 tracer from hydrochloric acid solution with the secondary amine, Amberlite IA-l in kerosene, has been reported by Ichikawa and Urono. (16) They demonstrated the mutual separation of protactinium, uranium, and thorium based on the inextractability of thorium from all hydrochloric acid concentrations and the preferential extraction of uranium over protactinium at $3 \underline{\mathrm{M}}$ hydrochloric acid.

\section{c. Sulfuric Acid Solution}

Protactinium-233 tracer has been found to extract efficiently from sulfuric acid solutions with methyl-di-n-octylamine-trichloroethylene. (49) In the system, 5\% methyl-di-n-octylamine-trichloroethylene, the extraction of protactinium-233 tracer was found to be $95 \%$ and $63 \%$ from $0.5 \mathrm{M}$ and $1.5 \mathrm{M}$ sulfuric acid solutions, respectively.

Ichikawa and Urono ${ }^{(16)}$ reported negligible extraction of protactinium(V) from sulfuric acid solutions using the secondary amine, Amberlite IA-I, in kerosene.

\section{d. Phosphoric Acid Solution}

Protactinium tracer has been reported ${ }^{(55)}$ to extract readily from dilute phosphoric acid solutions with methyl-di-n-octylamine-trichloroethylene. An equal volume portion extracted protactinium-233 tracer essentially quan- 
titatively in five minutes using $5 \%$ methyl-di-n-octylamine-trichloroethylene from an aqueous solution of $1.8 \mathrm{M}$ phosphoric acld. The extraction was also efficient from more dilute phosphoric acid solutions, but decreased at concentrations greater than $2 \underline{M}$.

\section{Trivalent Lanthanide and Actinide Elements}

\section{a. Nitric Acid Solution}

Few papers have reported the extraction of the trivalent lanthanide and actinide elements from nitric acid solution with high-molecular-weight amines. Lanthanide elements have been extracted from slightly acid nitrate solutions $(\hat{3}, 27)$ with tertiary amines; secondary and primary amines gave negligible extractions. Interestingly, the lanthanide sulfates are extracted only by the primary amines.

Keder, Sheppard, and Wilson ${ }^{(36)}$ compared the distribution ratios of americium(III) and plutonium(III) in $4 \underline{M}$ nitric acid solution using tri-noctylamine-xylene. In the system, 4 Mitric acid-10\% tri-n-octylaminexylene, the distribution ratios for americium(III) and plutonium(III) were $4 \times 10^{-4}$ and $3 \times 10^{-2}$, respectively.

Trilsooctylamine and tri-n-octylamine $(I \underline{M})$ in benzene have been shown to extract yttrium earths with separation from yttrium in nitrate solutions. $(3,27)$ The extraction increased with increased nitrate concentrations and decreased free acid concentrations, being very low with as much as $0.5 \mathrm{M}$ free nitric acid. Separation factors for dysprosium from yttrium using single-stage five minute batch equilibrations at a phase ratio of 1 gave values of 5.1 and 4.5, respectively.

\section{b. Hydrochloric Acid Solution}

Trivalent lanthanide and actinide elements do not form extractable anionic species in simple hydrochloric acid systems. However, a recent paper has described the high extractability of americium and curium in the system, hydrochloric acid-lithium chloride-trilsooctylamine. This liquid-liquid extraction technique has been proposed for the rapid separation of the trivalent actinide elements from the lanthanide elements. The method involves 
the preferential extraction of the trivalent actinide elements from dilute hydrochloric acid-concentrated lithium chloride solutions with trilsooctylamine dissolved in xylene or other solvents. Figure 2 shows the extraction of americium-241 and europium-152 tracers from lithium chloride solution with $20 \%$ trifsooctylamine-xylene. The order of decreasing extractability is

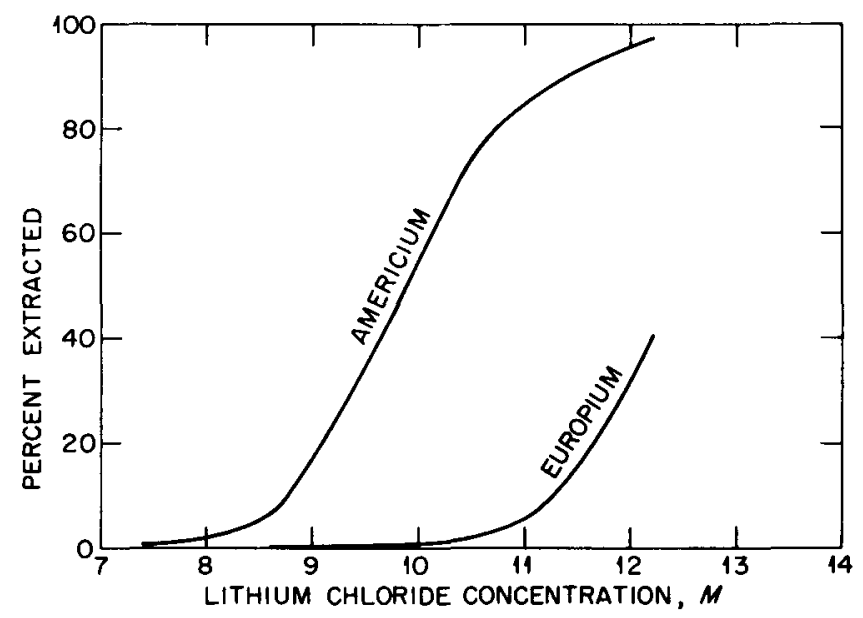

Fig. 2 Extraction of americium-241 and europium-152 tracers with $20 \%$ triisooctylamine-xylene.

americium, curium $>$ thorium $>$ europium, promethium $>$ cerlum $>$ yttrium, thulium. The technique has been demonstrated in the efficient separation of americium from promethium and the separation of americium and curium tracers from lanthanide tracer mixtures (See Selected Procedures). Apparently lithium chloride not only serves as a source of chloride ions, but the highly-hydrated lithium ion reduces the concentration of "free" water, thereby, promoting the formation of anionic chloro complex species of the actinide elements. Under the conditions used for trilsooctylamine, negligible extraction of the actinide elements was observed with the primary amine, $20 \%$ Primene JM-xylene or the secondary amine, 20\% Amine 9D-178-xylene.

It was also found possible to effect high extractions of trivalent lanthanide elements by selection of a suitable system. (38) For instance, in the system, $11.9 \underline{\mathrm{M}}$ lithlum chloride-0.1 $\underline{\mathrm{M}}$ hydrochloric acid-20\% trilsooctylamine-xylene, the extraction of europium-152 tracer was found to be $15.7 \%$. Under the same conditions and replacing the xylene with the diluents, methylene 
chloride, $\beta \beta^{\prime}$ dichloroethyl ether, and $n$-hexane, the europlum-152 tracer exhibited extractabilities of $91.3,63.1$, and $54.8 \%$, respectively. High extractions of the trivalent lanthanide chlorides were also possible with xylene as a diluent at very high concentrations of lithium chloride (Figure 2), higher concentrations of amine, and lower hydrochloric acid concentrations.

The use of high-molecular-weight amines dissolved in Amsco 125-82 has also been investigated $(56)$ as extractants for americium and trivalent lanthanide elements from lithium chloride solutions. Extractions from $10 \mathrm{M}$ lithium chloride solution were as follows: trilaurylamine, cerium $>$ amerlcium > europium; n-tetraheptyl-amonium chloride, europium > americium > certum.

\section{c. Sulfuric Acid Solution}

Primary amines have been shown ${ }^{(3)}$ to exhibit high extractability for trivalent lanthanide elements from aqueous solutions of 1 M sulfate, $\mathrm{pH} 1$, and $1 \mathrm{~g} / \mathrm{I}$ of metal ion using $0.1 \underline{\mathrm{M}}$ primary amine in an aromatic hydrocarbon diluent. Primary amines, such as Primene JM-T were found to give extraction coefficients $\left(E_{a}^{0}\right)$ of 20 (> 50 for cerium(IV)) while secondary and tertiary amines, in general, gave extraction coefficients of less than 0.1 and less than 0.01 , respectively.

Favorable extractions of trivalent lanthanide elements from thoriumand uranium-barren monazite sulfate liquors were effected (39) using a 0.2 M Primene JM-kerosene system. Extraction coefficients, although low, $\mathrm{E}_{a}^{0}=$ 0.3 at $\mathrm{pH} 0.2$ and $I$ at $\mathrm{pH} 0.4$ ) were adequate for process use. The lanthanide elements could be stripped readily with various reagents, including chloride, nitrate, carbonate and sulfuric acid solutions.

A recent paper ${ }^{(57)}$ has described the extraction of trivalent lanthanide elements from aqueous sulfate solutions at $\mathrm{pH} I$ with the primary amine, 0.2 M Primene 8LR in isopropyl ether. Separation factors for the lanthanide pairs, neodymium(III)-praseodymium(III) and cerium(III)-ytterbium(III) of 1.2 and 12 , respectively, were reported. 


\section{d. Thiocyanate Solution}

Two references give rather meager information on the extraction of the trivalent lanthanide and actinide elements in the thiocyanate system with amines. Extraction coefficients of approximately 0.3 were found $^{(44)}$ for americium-241 tracer in the system, 5\% methyl-di-n-octylamine-xylene-7-8 $\mathrm{M}$ ammonium thiocyanate. Under similar conditions, lanthanum-140 tracer was essentially inextractable and yttrium-9l tracer exhibited an extraction coefficient of approximately 0.3 .

In the system, $10 \%$ tri-n-octylamine-xylene- $5 \mathrm{M}$ amonium thiocyanate, an extraction coefficient of 0.5 was found ${ }^{(58)}$ for americium-241 tracer. No data for lanthanide elements were reported.

By analogy with anion exchange data, (59) it is suggested that by the use of higher concentrations of amines and selected acidities, one may effect useful extractions of trivalent actinide elements separated from the lanthanide elements.

\section{Neptunium and Plutonium}

\section{a. Nitric Acid Solution}

Wilson ${ }^{(60)}$ used $0.15 \mathrm{M}$ trilaurylamine in Amsco, containing $2 \%$ n-octyl alcoho] as an extractant for plutonium(IV) from $4 \underline{M}$ nitric acid-0.03 $\mathrm{M}$ sodium nitrite solutions of irradiated uranium. He achieved satisfactory separations of plutonium(IV) from uranium and fission products in a one-cycle process including two scrubs with $4 \underline{M}$ nitric acid. Fission product separation factors were: cerium, $2.3 \times 10^{7}$; ruthenium, $2.7 \times 10^{5}$; and zirconium-niobium, $2 \times 10^{4}$. Keder, Sheppard and Wilson ${ }^{(36)}$ used $10 \%$ tri-n-octylamine-xylene to extract neptunium(IV) and plutonium(IV) from nitric acid solutions. They found that the extractability of the tetravalent oxidation states of these elements was much greater than that of other oxidation states. The postulated species

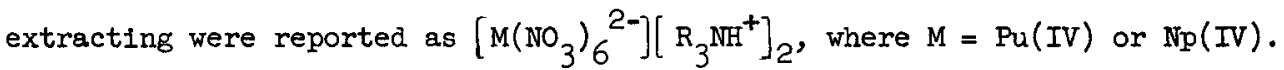
Winchester ${ }^{(61)}$ surveyed several plutonium recovery and puriffcation methods for plutonium-rich reactor fuels. He reported that solvent extraction of plutonium(IV) with the secondary amine, Amine 9D-178, was superior to 
tri-n-butyl phosphate extraction and to sorption by anion exchange resins or to precipitation of plutonium peroxide, oxalate and fluoride. The extraction coefficients for plutonium(IV), uranium(VI), and thorium(IV) from $8 \underline{\mathrm{M}}$ nitric acid were found to increase proceeding from the primary amine through the quaternary amine. Potential applications to the radiochemist are indicated.

Bertocci ${ }^{(62)}$ described the extraction of plutonium(IV) with triisononylamine-xylene both with and without uranium present.

Atwood and Snyder ${ }^{(17)}$ found that $10 \%$ trilaurylamine-xylene was a better solvent over other amine-diluent combinations for the extraction of plutonium(IV) from 2-10 M nitric acid solutions.

Brown and co-workers ${ }^{(63)}$ have reported the extraction of neptunium(IV) with several quaternary amonium salts. Neptunium(IV) extracted efficiently $\left(\mathrm{K}_{\mathrm{a}}^{\mathrm{O}}>20\right)$ from 0.1 to $10 \mathrm{~N}$ nitric acid solution with $0.1 \mathrm{M}$ tetraheptyl amonium nitrate in xylene. Highest extraction coefficlents were found at 1 M nitric acid (> 2000) with a sharp decrease with increasing acidity. In contrast, they found increasing extraction coefficients ( 380 at $2 \underline{M}$ and 760 at $8 \underline{M}$ nitric acid) with $0.2 \mathrm{M}$ didodecenyl dimethyl ammonium nitrate.

Neptunium(IV) has been shown $(32)$ to extract essentially quantitatively from nitric acid solutions of fluorination plant residues with $0.3 \mathrm{M}$ trilaurylamine-Amsco containing $5 \%$ tridecanol. The neptunium(IV) was stripped from the organic phase with $0.1 \mathrm{~N}$ sulfuric acid.

Recent studies ${ }^{(64)}$ have described the extraction of neptunium(IV) and plutonium(IV) from nitric acid solutions with organo-nitrogen compounds. In general, the order of extractability was: $\mathrm{Pu}(\mathrm{IV})>\mathrm{Pu}(\mathrm{VI}) \gg \mathrm{Pu}$ (III) and $\mathrm{Np}(\mathrm{IV})>\mathrm{Np}(\mathrm{VI}) \gg \mathrm{Np}(\mathrm{V})$. The extractants varied in the order: quatermary $>$ tertiary > primary, secondary.

Gaitanis ${ }^{(65)}$ has used $5 \%$ triisooctylamine-xylene in the extraction of plutonium(IV), thorium(IV), and uranium(VI) tracers from acid-deficient aluminum nitrate solutions.

Tetrabutylammonium nitrate diluted by a mixture of non-polar diluents 
(benzene and carbon tetrachloride) and polar ones (toluene, dibromoethane, and chloroform) has been used as an extractant for plutonium(IV) complexes from nftric acld solutions by Taube. ${ }^{(66)}$ Using a $1: 1$ volume ratio of chloroform and benzene containing $0.01 \mathrm{M}$ tetrabutylanmonium nitrate, he found that extraction coefficients were three or four times greater than for either pure solvent from $3 \underline{M}$ nitric acid solutions. Interaction of the polar plutonium(IV)-tetrabutylamonium nitrate complex with the diluent-nitric acid solvate was offered as a partial explanation of this phenomenon,

b. Hydrochloric Acid Solution

The extraction of plutonium(VI) tracer from hydrochloric acid solutions with 5\% tri-n-benzylamine-chloroform was observed in 1952. (19) A later paper ${ }^{(29)}$ described the extraction of plutonium(VI) tracer (> 99\%) from $4.8 \mathrm{M}$ hydrochloric acid solution with $5 \%$ trilsooctylamine-xylene (Table IX).

Table IX

\section{Extraction of Plutonium-239 Tracer From Hydrochloric Acid With 5\% \\ Trilisooctylamine-Xylene}

\begin{tabular}{|c|c|c|c|}
\hline Expt. & $\mathrm{K}_{2} \mathrm{Cr}_{2} \mathrm{O}_{7}, \underline{\mathrm{M}}$ & $\begin{array}{c}\text { Pu239 } \\
\text { Extracted, \% }\end{array}$ & Remarks \\
\hline 1 & 0 & 60.8 & -- \\
\hline 2 & 0.09 & 1.2 & $\begin{array}{l}\text { Organic phase cloudy } \\
\text { Slight ppt. in aqueous phase }\end{array}$ \\
\hline 3 & 0.05 & 83.2 & Some reduction or $\mathrm{K}_{2} \mathrm{Cr}_{2} \mathrm{O}_{7}$ \\
\hline 4 & 0.02 & 98.9 & $\begin{array}{l}\text { Clear phases; very slight amount } \\
\text { of } \mathrm{K}_{2} \mathrm{Cr}_{2} \mathrm{O}_{7} \text { reduction }\end{array}$ \\
\hline 5 & 0.01 & 99.8 & $\begin{array}{l}\text { Clear phases, no } \mathrm{K}_{2} \mathrm{Cr}_{2} \mathrm{O}_{7} \text { reduc- } \\
\text { tion }\end{array}$ \\
\hline $6^{a}$ & 0.01 & 99.8 & \\
\hline \multicolumn{4}{|c|}{ Molarity of hydrochloric acid was 6.4 . } \\
\hline
\end{tabular}




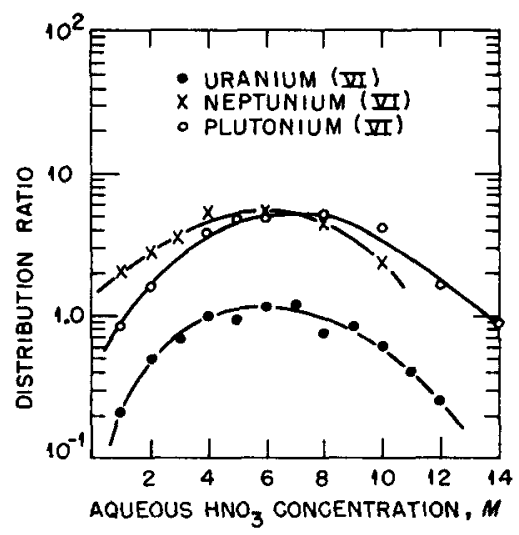

Flg. 3 The extraction of the hexavalent actinide nitrates by $10 \mathrm{v} / \mathrm{O}$ TOA in xylene.

coefficients of uranium(VI) are lower still, permitting an easy separation of neptunium(IV) and plutonium(IV) from uranyl nitrate solutions.

Bertocci (62) has studied the extraction of uranium(VI) with triisononylamine-xylene and suggested the compound formed was an amine-uranyl-trinitrate complex, TNA $\cdot \mathrm{HUO}_{2}\left(\mathrm{NO}_{3}\right)_{3}$.

Uranium(VI), along with neptunium(IV) and technetium(VII), has been found to extract ${ }^{(32)}$ essentially quantitatively from nitric acid solutions of fluorination plant residues by use of $0.2 \mathrm{M}$ trilaurylamine in Amsco-95 containing $5 \%$ tridecanol. These elements could be stripped from the organic phase consecutively with $0.5 \underline{N}$ nitric acid, $0.1 \underline{N}$ sulfuric acid and $I \underline{N}$ ammonium hydroxide, respectively.

The extractant, 20\% triisooctylamine-xylene has been used (37) for the extraction of uranium(VI) from acid-deficient aluminum nitrate solutions and subsequent determination by a controlled-potential coulometric titration method.

Kaplan, Hildebrandt, and Ader ${ }^{(68)}$ found an enhanced extraction of uranyl nitrate into ketonic solvents in the presence of substituted ammonium nitrates and demonstrated that the extractable complex was $\mathrm{RUO}_{2}\left(\mathrm{NO}_{3}\right)_{3}$ in which the uranium was present as an anion.

Haeffner, Nilssen and Hultgren ${ }^{(69)}$ used tetrabutylammonium nitrate effectively in the extraction of uranyl nitrate with chloroform. 
twice with equal volume portions of $5 \underline{M}$ hydrochloric acid solution and stripping the plutonium into $0.1 \mathrm{M}$ hydrochloric acid solution. The dichromic acid, used as a holding oxidant for plutonium(VI), was found to extract initially but remained in the organic phase when the plutonium was stripped. Neptunium would behave similar to plutonium or uranium of the same oxidation state.

\section{c. Sulfuric Acid Solution}

The extraction of neptunium(IV) and plutonium(IV) from sulfuric acid solutions was found to be high ${ }^{(64)}$ using the primary amine, Primene Ji-T $x$

in xylene or Amsco. The extraction of neptunium(IV) was considerably higher than that of plutonium(IV). In general, the extractability of neptunium(IV) and plutonium(IV) from sulfate solution was found to be: primary $\gg$ secondary $>$ tertiary amine.

\section{a. Acetic Acid Solution}

Plutonium(VI) has been found to extract efficiently (97-98\%) from an aqueous solution of 1 M acetic acid with $20 \%$ trilsooctylamine-xylene containing 3\% butyl Cellosolve. (67) Plutonium(III) was essentially inextractable $(<1 \%)$ and plutonium(IV) was weakly extracted (1.9\%) under slmilar conditions. Neptunium(VI) would behave similar to plutonium(VI) in this system.

\section{Uranium}

A striking property of the uranyl ion in aqueous solution is its capacity of forming extractable anionic complexes in most acid systems. $(3,19)$

\section{a. Nitric Acid Solution}

The extraction of uranium(VI) from 6 M nitric acid solution with tri-noctylamine in xylene ${ }^{(36)}$ and Amsco D-95 ${ }^{(3)}$ has been reported. In the system, $10 \%$ tri-n-octylamine-xylene, the extraction data for uranium(VI), neptunium(VI) and plutonium(VI) are shown in Figure 3 (taken from data of Keder, Sheppard, and Wilson ${ }^{(36)}$ ). The extraction coefficients of neptunium(VI) and plutonium(VI) are quite similar and are ten to one hundred times less than those for the tetrapositive oxidation states of these elements. The extraction 
Maeck and co-workers $(70)$ described the extraction of tetrapropylammonium uranyl trinitrate with methyl isobutyl ketone from an acid-deficient aluminum nitrate solution. The recovery of uranium was reported to be essentially quantitative with less than one per cent of one year cooled fission products extracting. These workers found the method highly selective for the separation of uranium from diverse ions. They ${ }^{(71)}$ used the technique in spectrophotometric methods involving a direct measurement of the absorbancy of the uranyl trinitrate complex in the separated organic phase for milligram levels. Microgram amounts of uranium were determined by adding dibenzoylmethane in an ethyl alcohol-pyridine mixture to the separated organic phase and measuring the absorbance of the chelate.

\section{b. Hydrochloric Acid Solution}

Bailes $(72)$ has reported the use of the secondary amine, Amine 9D-178, dissolved in toluene as an extractant for uranium(IV) and uranium(VI) from hydrochloric acid solutions. He found greater extraction coefficients for uranium(VI) than uranium(IV) at a given hydrochloric acid concentration.

Moore ${ }^{(29)}$ employed triisooctylamine dissolved in xylene or methyl isobutyl ketone for the rapid extraction of uranium(VI) and/or plutonium(VI) from hydrochloric acid solution. Under specified conditions an excellent separation of uranium may be effected from thorium, alkalies, alkaline earths, lanthanides, trivalent actinides, zirconium, niobium, ruthenium and many other elements which do not form extractable anionic chloro species. The technique is equally useful for tracer or macro amounts of uranium. Several practical applications of the method are described under "Selected Procedures." Figure 4 shows the extraction of uranium-233 tracer with 5\%

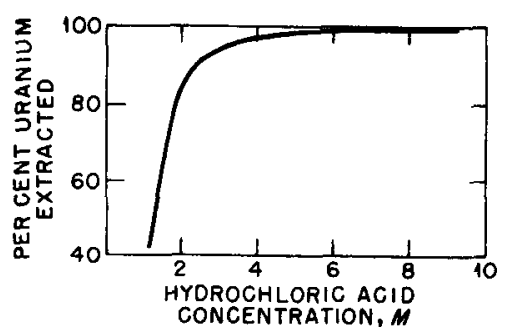

Fig. 4 Extraction of uranium-233 tracer with $5 \%$ triisooctylamine-xylene from hydrochloric acid solution. 
trifsooctylamins-xylene as a function of hydrochloric acid concentration.

Tables IV and $V$ indicate the extraction of thorium and some typical fission products. Thus, by extracting from an aqueous solution of $5 \underline{M}$ hydrochloric acid, only ruthenium and niobium extract appreciably. The niobium may be scrubbed from the organic phase with $5 \underline{M}$ hydrochloric ac1d solution. The ruthenium remains in the organic phase when the uranium is stripped into $0.1 \mathrm{M}$ hydrochloric acid solution. Tables $\mathrm{X}, \mathrm{XI}$, and XII show the extraction of macro quantities of uranium from hydrochloric acid solution with trilsooctylamine dissolved in various diluents.

Table $x$

\section{Extraction of Macro Quantities of Uranium From Hydrochloric Acid With 5\% \\ Trilsooctylamine-Xylene}

\begin{tabular}{|c|c|c|c|c|}
\hline Expt. & $\mathrm{HCl}, \underline{\mathrm{M}}$ & $\begin{array}{l}\text { Uranium } \\
\text { Concn., } \\
\text { Mg./Ml. }\end{array}$ & $\begin{array}{c}\text { Uranium } \\
\text { Extracted, } \\
\text { \% }\end{array}$ & Remarks \\
\hline 1 & 4 & 1 & $97.9]$ & \\
\hline 2 & 6 & 1 & 99.1 & Excellent phase behavior \\
\hline 3 & 6 & 2 & 99.0 & \\
\hline 4 & 6 & 3.9 & 99.0 & \multirow{3}{*}{$\begin{array}{l}\text { Yellow ofl containing uranium } \\
\text { observed at bottom of organic } \\
\text { phase }\end{array}$} \\
\hline 5 & 6 & 7.8 & 98.2 & \\
\hline 6 & 6 & 11.7 & 87.6 & \\
\hline 7 & 7.6 & 11.7 & 94.4 & $\begin{array}{l}\text { Phase behavior much better than } \\
\text { in expt. } 6\end{array}$ \\
\hline 8 & $4.8^{a}$ & 10.6 & 93.67 & \multirow{2}{*}{ Excellent phase behavior } \\
\hline 9 & 9 & 2.1 & 99.0 & \\
\hline 10 & 9 & 4.2 & 98.8 & $\begin{array}{l}\text { Yellow ofl containing uranium } \\
\text { at bottom of organic phase }\end{array}$ \\
\hline 11 & 10 & 4.2 & 98.1 & Excellent phase behavior \\
\hline 12 & 9 & 8.4 & 97.9 & $\begin{array}{l}\text { Clear phases; yellow oil at } \\
\text { interface }\end{array}$ \\
\hline 13 & 9 & 16.8 & 82.7 & Gel at interface \\
\hline
\end{tabular}


Table XI

Extraction of Uranium From Hydrochloric

Acid with 5\% Trilsooctylamine

in Varlous Solvents ${ }^{a}$

\begin{tabular}{|c|c|c|}
\hline Solvent & $\begin{array}{l}\text { Uranfum } \\
\text { Extracted, }\end{array}$ & Remarks \\
\hline DA1sobutylcarbinol & 59.0 & Clear phases, organic viscous \\
\hline D1sopropyl ketone & 94.7 & $\begin{array}{l}\text { Slight amount yellow oil at } \\
\text { interface }\end{array}$ \\
\hline Methyl isobutyl ketone & 93.5 & Excellent phase behavior \\
\hline Carbon tetrachloride & 94.7 & Yellow gel at interface \\
\hline Amsco $125-82$ & 99.0 & Yellow gel at interface \\
\hline Xylene & $97 \cdot 9$ & Yellow gel at interface \\
\hline $\begin{array}{l}\text { Xylene-methyl isobutyl } \\
\text { ketone ( } 1 \text { to } 1 \text { ) }\end{array}$ & 97.0 & $\begin{array}{l}\text { Very slight amount of solid } \\
\text { at interface }\end{array}$ \\
\hline $\begin{array}{l}\text { Xylene-methyl isobutyl } \\
\text { ketone ( } 4 \text { to } 1 \text { ) }\end{array}$ & 97.4 & $\begin{array}{l}\text { Small amount of solid at } \\
\text { interface }\end{array}$ \\
\hline
\end{tabular}

Each aqueous phase contained $8.4 \mathrm{mg}$. per $\mathrm{ml}$. of uranium in $9 \underline{\mathrm{M}}$ hydrochloric acid before extraction.

Table XII

Extraction of Macro Quantities of Uranium

From 9 M Hydrochloric Acid with $20 \%$

Triisooctylamine in Various Solvents

\begin{tabular}{|c|c|c|c|}
\hline $\begin{array}{c}\text { Uranium } \\
\text { Concn. } \\
\text { Mg. MI. }\end{array}$ & Solvent & $\begin{array}{c}\text { Uranium } \\
\text { Extracted, } \\
\phi_{0}\end{array}$ & Remarks \\
\hline
\end{tabular}

\begin{tabular}{|c|c|c|c|}
\hline 15.1 & Xylene & 99.2 & Excellent phase behavior \\
\hline \multirow[t]{3}{*}{30.2} & Xylene & 99.0 & $\begin{array}{l}\text { Heavy liquid at inter- } \\
\text { face }\end{array}$ \\
\hline & Methyl isobutyl ketone & 98.5 & Excellent phase behavior \\
\hline & $\begin{array}{l}\text { Xylene-methyl isobutyl } \\
\text { ketone ( } 1 \text { to } 1 \text { ) }\end{array}$ & 99.0 & $\begin{array}{l}\text { Slight amount of solid } \\
\text { at interface }\end{array}$ \\
\hline \multirow[t]{3}{*}{45.3} & Xylene & 97.4 & Gel at interface \\
\hline & Methyl isobuty- ketone & 97.5 & Excellent phase behavior \\
\hline & $\begin{array}{l}\text { Xylene-methyl isobutyl } \\
\text { ketone ( } 1 \text { to } 1 \text { ) }\end{array}$ & 98.1 & $\begin{array}{l}\text { Small amount of solid } \\
\text { at interface }\end{array}$ \\
\hline \multirow[t]{3}{*}{60.4} & Xylene & 95.6 & Heavy gel at interface \\
\hline & Methyl isobutyl ketone & 94.4 & Excellent phase behavior \\
\hline & $\begin{array}{l}\text { Xylene-methyl isobutyl } \\
\text { ketone ( } 1 \text { to } 1)\end{array}$ & 95.9 & $\begin{array}{l}\text { Slight amount of solid } \\
\text { at interface }\end{array}$ \\
\hline
\end{tabular}


Trilsooctylamine-xylene has been used in a procedure by Laux and Brown (

for the quantitative separation of uranium from zirconium from $4 \underline{M}$ hydrochloric acid solution and subsequent colorimetric determination of the latter by the Alizarin red $S$ method.

Webster and co-workers $(74)$ in a recent paper described the use of $5 \%$ triisooctylamine-xylene in the separation of uranium from fission products prior to the determination of uranium-235 by the isotope dilution method.

Reynolds and Eldridge ${ }^{(75)}$ used $8 \%$ tri-n-benzylamine-chloroform to extract uranium from $8 \mathrm{M}$ hydrochloric acid solution prior to the determination of uranium-235 abundance by garma spectrometry.

The extraction of uranium(VI) from hydrochloric acid solutions by trin-octylamine-carbon tetrachloride was described by Bizot and Tremillon. (76) They proposed the formula for the extractable complex as $\left(\mathrm{R}_{3} \mathrm{NHCl}_{2} \mathrm{UO}_{2} \mathrm{Cl}_{2}\right.$, where $R_{3} N=$ tri-n-octylamine.

Ichikawa and Urono ${ }^{(16)}$ reported that the extraction of uranium(VI) from hydrochloric acid solution with the secondary amine, Amberlite LA-1, in kerosene was superior to that from other acid systems. They satisfactorily separated uranium, protactinium and thorium from each other and reported higher selectivity for uranium in hydrochloric acid solution with amires than with solid anion resins.

\section{c. Sulfuric Acid Solution}

The use of high-molecular weight amines as extractants for uranium has concentrated in the sulfate system. Since the first observation (19) on the extraction of uranium(VI) from sulfuric acid solution about 1950, numerous papers have appeared describing various systems. An excellent review of the work at Oak Ridge National Laboratory, where the early work was centered, has been reported by Coleman, Brown, Moore, and Crouse. (3) These workers screened more than two hundred organo-nitrogen compounds and found the following amines among the best for the selective extraction of uranium from most contaminants: tri-n-octylamine, trissooctylamine, trilaurylamine, tri-nbenzylamine, tris(2-ethylhexyl)amine, methyldilaurylamine, butyldilaurylamine, 
dilaurylamine, Amine 9D-178, octadecylamine and n-benzylheptadecylamine. The very high extracting power of the latter reagent has been used to concentrate very dilute uranium solutions for analysis. (77) As a result of these studies, the Amex process was developed and is now employed in several mills for the refining of uranium. Briefly, this process utilizes the high selectivity of the secondary or tertiary amines ( $0.1 \mathrm{M}$ in kerosene or hydrocarbon diluents) for uranyl sulfate to produce high quality uranium concentrates from relatively low grade highly-contaminated sulfuric acid leach liquors. $(78,79,80)$ The uranium is essentially quantitatively extracted from the leach liquor in three to five stages of conventional counter-current extraction equipment. The aqueous-organic feed ratios are adjusted to give solvent loadings about $90 \%$ of the maximum possible. Uranium is then stripped into a much smaller volume using two or three stages. After nitrate (or chloride) stripping, a regeneration step with ammonium hydroxide removes the nitrate ion before recycle of the amine solution. The uranium product contains not more than a few per cent of impurities. Increased purity of the product is possible by scrubbing the loaded organic solution before stripping. An important advantage in the use of tertiary or secondary amines is the efficient separation of uranium from iron(III) without necessity of reducing the iron as is required in several other techniques.

Preuss and Sanders ${ }^{(81)}$ screened fifty amines as extractants for uranium from sulfuric acid solutions. The most promising were: tri-n-octylamine, dodecenyl alkylamine-81, dodecenyl alkylamine-JM, Armeen 2-212, dodecenyl laurylamine, Primene JMR and didodecenyl n-butylamine. These reagents satisfactorily extracted uranium from actual leach liquors containing 0.67 $\mathrm{g} / 1$ uranium, $2.53 \mathrm{~g} / 1$ iron(III), approxinately $40 \mathrm{~g} / 1$ sulfate at a $\mathrm{pH}$ of 1.5 .

Hassialis and co-workers ${ }^{(82)}$ studied the recovery of uranium from Chattanooga shale sulfate leach liquors. They found that n-benzyl-1-(3-ethyl pentyl)-4-ethoxyoctylamine (NBA) dissolved in kerosene was a highly efficient and selective reagent. Table XIII shows typical data these workers found. 


\section{Solvent Extraction of An Oxygen \\ Pressure Leach Liquor}

Conditions: $\mathrm{pH}-\sim 1.0$, Phase Ratio $=1$, Extractant $0.05 \mathrm{M} \mathrm{NBA}$ in kerosene

\begin{tabular}{lcc}
\hline Species & Feed Conc., mg/l. & Ext'n. Coeff., $\mathrm{E}_{\mathrm{a}}^{\circ}$ \\
\hline $\mathrm{U}$ & 47.5 & 350 \\
$\mathrm{Fe}^{++}$ & 3,700 & 0.001 \\
$\mathrm{Fe}$ (Total) & 15,300 & 0.015 \\
$\mathrm{Mo}$ & 32 & 0.81 \\
$\mathrm{Al}^{-=}$ & 5,000 & 0.005 \\
$\mathrm{So}_{4}$ & 114,000 & 0.037
\end{tabular}

Petrow and co-workers ${ }^{(83)}$ evaluated several commercially available amines ( $0.1 \mathrm{M}$ in Amsco 125) as uranium extractants from $0.5 \mathrm{M}$ sulfuric acid leach liquors. Satisfactory amines were found to be Amine 9D-178, Amine S-24, triisooctylamine, trilaurylamine, Amine RC-3749, Amine D-205, Amine 7F-802 and n-benzylheptadecylamine.

Recently Brown and Crouse ${ }^{(84)}$ have reported a liquid-liquid extraction process for recovering uranium and thorium from monazite sulfate liquors. The process gives essentially clean and complete recoveries of uranium and thorium, an advantage over conventional precipitation processes. Thorium is extracted in the first cycle with a primary amine in a hydrocarbon diluent and uranium in the second cycle with a secondary or tertiary amine in a hydrocarbon diluent.

Bellingham and Simard ${ }^{(85)}$ described the stripping of uranium(VI) from 0.1 N triisooctylamine-kerosene loaded with uranyl sulfate. They demonstrated that sodium sulfate stripping of uranium from the amine extractant was simpler and cheaper than by chloride or carbonate solutions.

High extractability of uranium(IV) from sulfate solutions with various primary amines dissolved in kerosene has been reported. (3) Extraction coeffi- 
cients of 3000-5000 for several primary amines were found. Extraction coefficients were lower with secondary emines (50-200) and much lower $(<1)$ with tertiary amines. However, the use of primary or secondary amines for the extraction of uranfum(IV) from sulfate solution is known to be much less selective than systems Involving the extraction of uranium(VI) with tertiary amines, particularly in reference to iron(III), titanium(IV), zirconium-hafnium(IV), thorium(IV) and trivalent lanthanide elements.

\section{d. Acetic Acid Solution}

The efficient extraction of uranium(VI) from dilute acetic acid solutions with methyl-di-n-octylamine-xylene ${ }^{(19)}$ and with tri-n-octylamine-Amsco (3) has been reported.
A recent paper $(67)$
has described the extraction of uranium(VI) from acetate solution with triisooctylamine dissolved in xylene containing $3 \%$ butyl Cellosolve or other solvents. Uranium and/or plutonium are separated from thorium, alkalies, alkaline earths, lanthanides, trivalent actinides, zirconium, hafnium, niobium, tantalum, ruthenium, iron, protactinium, lead, nickel, cobalt, manganese, chromium, aluminum, copper, zinc, bismuth, tin, and antimony. The technique is suitable for either tracer or macro amounts of uranium. The extraction of uranium-233 tracer with $5 \%$ triisooctylaminexylene as a function of acetic acid concentration is shown in Figure $5 .(67)$

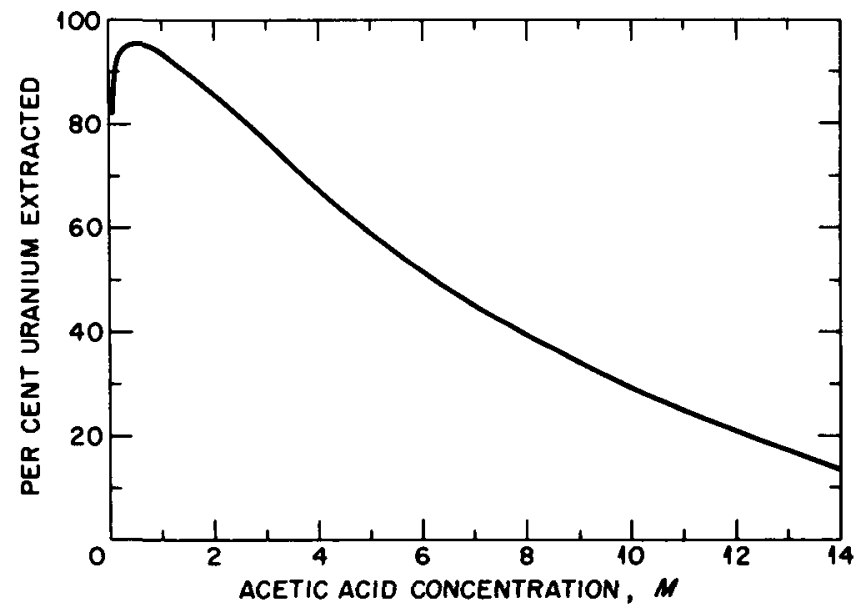

Fig. 5 Extraction of uranium- 233 tracer with $5 \%$ triisooctylamine-xylene from acetic acid solution. 
Optimum extraction occurs in the range $0.5-1$ M acetic acid. The uranium-233 tracer may be stripped from the organic phase essentially quantitatively with equal volume portions of $6 \underline{M}$ sulfuric acid, $1 \underline{M}$ ammonium bicarbonate, concentrated amonium hydroxide, or $0.25 \mathrm{M}$ hydrofluoric acid-0.25 M nitric acid solutions. Table XIV shows the extraction of macro quantities of uranium from acetic acid sclutions with trisooctylamine-xylene. Increased selectivity may be effected by using a preliminary hydroxide precipitation of uranium, followed by dissolution in $1 M$ acetic acid solution and extraction of the solution under the conditions cited above. (See "Selected Procedures")

Table XIV

Extraction of Macro Quantities of Uraniun From Acetic Acid With TriisooctylamineXylene Solution

\begin{tabular}{cccc}
\hline $\begin{array}{c}\text { Acetic } \\
\text { Acid } \\
\mathrm{M}\end{array}$ & $\begin{array}{c}\text { Triisooctylamine } \\
\text { in Xylene, } \\
\%\end{array}$ & $\begin{array}{c}\text { Uranium } \\
\text { Concn. } \\
\mathrm{Mg} . / \mathrm{Ml} .\end{array}$ & $\begin{array}{c}\text { Uranium } \\
\text { Extracted, } \\
\%\end{array}$ \\
\hline 0.5 & 20 & $u^{233}$ tracer & 99.4 \\
0.5 & 20 & 3.46 & 97.9 \\
0.5 & 20 & 5.86 & 96.2 \\
0.5 & 20 & 6.92 & 94.8 \\
1 & 20 & $U^{233}$ tracer & 99.5 \\
1 & 30 & $U^{233}$ tracer & 99.6 \\
1 & 20 & 2 & 99.1 \\
1 & 20 & 5 & 98.7 \\
1 & 30 & 5 & 99.1 \\
1 & 20 & 10 & 97.6 \\
1 & 20 & 15 & 97.3
\end{tabular}

The possibility of extracting uranyl triacetate by aniline has been shown by Vdovenko and Lazarev. (86)

\section{e. Other Acid Systems}

High extractability of anionic uranyl species with methyl-di-n-octylamine-xylene has also been reported ${ }^{(19)}$ possible from dilute solutions of 


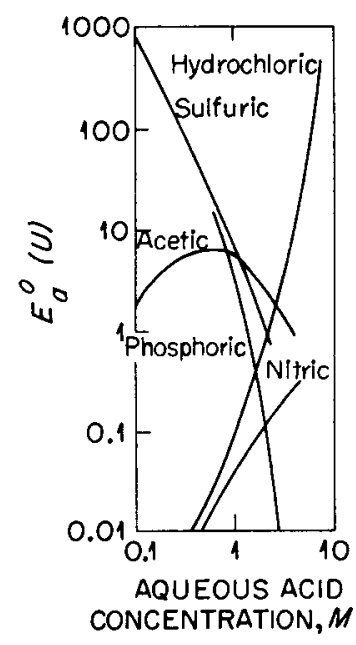

A

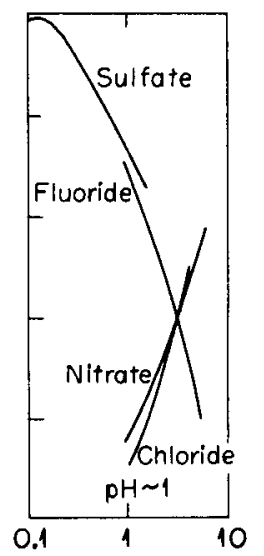

AQUEOUS SALT

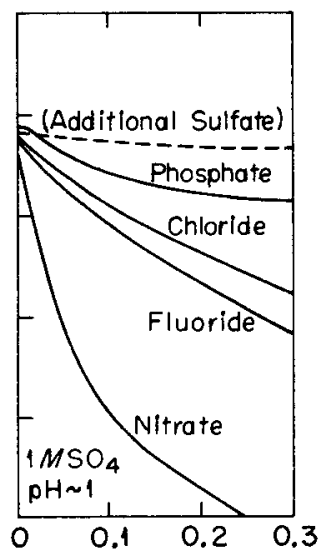

CONCENTRATION OF

ADDED ANION, $M$

$B$

C

Fig. 6 Uranyl extraction increases at high concentrations of weakly complexing anions, decreases at high concentrations of strongly complexing anions, and usually decreases on addition of other anions to a sulfate solution ( $0.1 \mathrm{M}$ tri- $n$-octylamine-Amsco D-95 and methyl di-n-decylamine-benzene).

these acids: phosphoric, oxalic, hydrofluoric, formic and maleic. The extraction of uranium(VI) from several acid systems is shown in Figure 6 (taken from data of coleman, C. F. and co-workers $\left.{ }^{(3)}\right)$. They found that the amine extraction of uranium(VI) from phosphate or fluoride solution was qualitatively similar to the extraction from sulfate solution. A relatively low concentration of these anions is sufficient to give an extractable uranyl complex and higher concentrations merely compete. In contrast, the extraction is very low from dilute chloride or nitrate solutions, increasing with increasing anion concentration since relatively high concentrations of these are necessary for suitable complex formation. Interesting details regarding the effect of various anions on the extraction of uranium(VI) from sulfate solutions are reported by these workers.

Ellis, Long and Magner ${ }^{(87)}$ found favorable extractions of uranium(VI) from water and dilute hydrofluoric acld solutions with long-chain alkyl amines. The presence of hydrochloric acid interfered with the formation of the extractable uranyl fluoride complex. Hydrofluoric acid-treated amines 
extracted uranium far better from water than from hydrofluoric acid aqueous solutions. Using 10\% Amine 9D-178-toluene (pretreated with hydrofluoric acid), they found extraction coefficients of uranium from water, 1 M hydrofluoric acid and $2 \mathrm{M}$ hydrofluoric acid to be 180,24 and 18 , respectively. Repeating the same experiments with the amine solvent pretreated with hydrochloric acld gave extraction coefficients of $0.0006,2.3$ and 2.2 , respectively.

Recently, Ziegler ${ }^{(21)}$ found that the uranyl ion forms a more intensely yellow color with thiosulfate than it does in mineral acid solutions. The complex can be extracted quantitatively with various amines or substituted ammonium salts.

\section{f. Alkaline Solutions}

Clifford and co-workers ${ }^{(88)}$ described the extraction of uranium(VI) from carbonate solutions by means of a complex salt with 8-quinolinol and a quaternary ammonium ion. The extraction is based on the novel uranyl chelate, $\mathrm{UO}_{2}\left(\mathrm{C}_{9} \mathrm{H} \mathrm{ON}_{3}^{-}\right.$formed. The extraction coefficients increased as the $\mathrm{pH}$ was varied from 10 to 12.5. High-molecular-weight quaternary ammonium cations were most effective, such as Arquad $2 \mathrm{C}, \mathrm{R}_{2} \mathrm{~N}\left(\mathrm{CH}_{3}\right)_{2} \mathrm{Cl}$, where $\mathrm{R}$ averages about a 26-carbon chain. Methyl isobutyl ketone was an effective solvent. The species extracted was found to be $\mathrm{R}_{4} \mathrm{NUO}_{2}(\mathrm{OX})_{3}$. The uranium could be stripped from the organic phase with strong acids, but the 8 quinolinol was removed also. The most effective strippant was found to be sodium bicarbonate solutions on a countercurrent basis. These workers also reported that substantial extraction of uranium with organic solutions of quaternary ammonium cations could be effected with the complexing agents: benzoin 2-oxime, cupferron, peroxide, pyrogallol and hydroxylamine.

The extraction of the uranyl ion from aqueous solutions of $1.1 \mathrm{~g} / \mathrm{l}$ uranium, $0.5 \mathrm{M}$ sodium carbonate, $\mathrm{pH} 10.7$ with the quaternary ammonium compound, B-104 (10\% in Amsco G) has given (31) an extraction coefficient of 4.3. These workers ${ }^{(32)}$ have more recently used the quaternary ammonium compound, Aliquat 336, dissolved in kerosene-tridecanol for the extraction of uranium from carbonate solutions. 


\section{Miscellaneous Extractions}

The large amine dye cations, such as Rhodamine $B$, will extract anionic species $\left(\mathrm{TlCl}_{4}{ }^{-}, \mathrm{TlBr}_{4}^{-}, \mathrm{FeCl}_{4}{ }^{-}, \mathrm{FeBr}_{4}{ }^{-}, \mathrm{SbCl}_{6}^{-}, \mathrm{SbBr}_{6}^{-}, \mathrm{AuCl}_{4}^{-}\right.$) into various organic solvents forming colored complexes useful for photometric analysis. No application of these dyes in radiochemical separation work has been reported. This topic is reviewed by Morrison and Freiser. (1)

In a novel application, the primary amine, Primene 81-R, in methanol has been used for the trapping and liquid scintillation counting of $\mathrm{C}^{14} \mathrm{O}_{2}$ by Oppermann and co-workers. (89) They found that this amine reagent had a great affinity for $\mathrm{C}^{14} \mathrm{O}_{2}$ allowing fast absorption, good recovery, and little or no quenching. This liquid-gas extraction technique for acidic radioactive gases would appear to be a significant advance over some of the present cumbersome and time-consuming methods.

The physical chemist may find these "liquid anion exchangers" useful. They can be used for studies of equilibria in concentrated solutions of electrolytes without Donnan penetration of the exchanger phase. The rates of exchange are usually faster, and measurements of physical properties and analysis of exchangers are more conveniently performed than with solid exchangers. For example, it is difficult to study the effect of concentration of the active groups of the solid anion exchangers on the absorption of ions from solution. With the "liquid anion exchangers" this can be done easily, because simply by diluting the organic phase, the concentration of active groups can be varied over a wide range.

A note of caution is in order regarding the use of high-molecularweight amines. Numerous amines are now available commercially, and the chemist should exercise discretion in the choice of a new reagent in development work. Depending on the application, several factors dictate the selection of amine. (3) For example, high losses due to excessive aqueous solubility may render one amine uneconomical for the processor; on the other hand, the analytical chemist may use the same reagent profitably. The amines described in this monograph have been carefully evaluated for the prescribed 
application, and the reader is referred to the specific references for details.

There exists a tremendous amount of work with solld anion exchange resins as separations tools. Often the high-molecular-weight amines can be substituted for the solid exchangers with significant advantages. The amines combine the chemical virtues of anion exchange resins and the physical virtues of solvents. (13) The liquid-liquid extraction technique is versatile, fast, inexpensive, and has higher capacities for metal ions, generally. Also, it possesses the inherent advantage of greater ease of operation of a liquid-liquid system over a solid-liquid system in continuous counter-current work.

\section{Acknowledgement}

The author is indebted to the many colleagues who have kindly provided material, some in advance of publication, for this manuscript. The assistance of Mrs. M. L. Bevan in preparation of the manuscript is gratefully acknowledged.

IV. COLIECTION OF SELECTED PROCEDURES

PROCEDURE 1

Separation of Trivalent Actinide Elements From Lanthanide Elements

Source: Moore, F. L. (to be published in Anal. Chem.), Oak Ridge National Laboratory (1960).

A liquid-liquid extraction method for the rapid separation of the trivalent actinide elements from the lanthanide elements has been developed. The method involves the preferential extraction of the trivalent actinide elements from dilute hydrochloric acid-concentrated lithium chloride solution with triisooctylamine dissolved in xylene or other solvents.

\section{Procedure}

An aqueous solution of tracer amounts of the trivalent actinide and lanthanide elements is prepared in strong lithium chloride-dilute hydro- 
chloric acid solution. This solution should be prepared free of anions other than chloride and of cations forming chloride complexes, especially iron, uranium, protactinium, neptunium, plutonium, zirconium, niobium, and ruthenium. Various methods may be employed to isolute the actinide-lanthanide(III) group. One useful technique is the conventional caxrying on lanthanum fluoride followed by lanthanum hydroxide precipitation and dissolution in hydrochloric acid.

Several combinations of variables may be used for the actinide(III)lanthanide(III) group separation. The technique is illustrated in the following two demonstrations:

\section{A. Separation of Promethium From Americium}

In a typical experiment an aqueous solution containing americium-24I $\left(3.1 \times 10^{5}\right.$ gamma counts per min.) and promethium-148(3.6 $10^{5}$ gamma counts per min.) in $10.5 \mathrm{M}$ lithium chloride and $0.002 \mathrm{M}$ hydrochloric acid was extracted for 2 minutes at room temperature with an equal volume portion (10 ml.) of $20 \%$ (w./v.) triisooctylamine-xylene. The organic phase was previously pretreated by mixing for several minutes with an equal volume portion of $2 \underline{M}$ hydrochloric acid solution. The extraction was repeated with two fresh portions of solvent. Analysis of the phases indicated an extraction of americium-241 tracer of $>98 \%$. The loss of promethium from the aqueous solution was approximately $6 \%$.

B. Separation of Americium and Curium Tracers from a Rare Earth Tracer Mixture

A solution containing americium-241 (3.9 $10^{5}$ alpha counts per min.), curium-244 ( $1.6 \times 10^{4}$ alpha counts per min.), and lanthanide tracers $(2.7 \times$ $10^{5}$ gamma counts per minute of approximately equal amounts of cerium-144, prometnium-148, europium-152, yttrium-91, and thulium-170) was adjusted to a concentration of $11.7 \mathrm{M}$ lithium chloride and $0.1 \mathrm{M}$ hydrochloric acid. The aqueous solution was extracted for two minutes with an equal volume portion ( $12 \mathrm{ml}$.$) of 20 \%$ trilsooctylamine-xylene. After separation of the 
phases, the aqueous phase was extracted with a fresh portion of solvent. The organic phases were combined and scrubbed twice with equal volume portions of $12 \mathrm{M}$ lithium chloride solution. Analysis of the organic phases indicated an average recovery of $96.5 \%$ americium and curium containing $3.1 \%$ of the rare earth tracers. Further scrubbing or recycling through the procedure may be used to increase the separation from the lanthanides.

\section{PROCEDURE 2}

Determination of Total Plutonium(IV), Thorium(IV), and Uranium(VI) Alpha Radioactivities

Source: Gaitanis, M. J., private communication (Nov. 15, 1960).

The following procedure has been found to be useful for the determination of Eross alpha radioactivities of tracer concentrations of plutonium(IV), thorium(IV), and uranium(VI). It has been observed that neptunium(V) does not extract under the conditions used. The method affords essentially quantitative recovery of these tracers from a variety of process solutions containing high concentrations of solids which would interfere in direct gross alpha determinations. After the aliquot taken for analysis is adjusted to the described acid deficiency, it is important that the extraction be performed immediately because of the possible formation of inextractable basic or polymeric species.

\section{Reagents}

Basic Aluminum Nitrate Solution (2.5 M Al and $1.0 \mathrm{M} \mathrm{Bas1c)}$. Dissolve $187 \mathrm{~g}$. of $\mathrm{Ar}\left(\mathrm{NO}_{3}\right) \cdot 9 \mathrm{H}_{2} \mathrm{O}$ in $100 \mathrm{ml}$. of distilled water by warming on a hot plate. Cool the solution to room temperature and add $13.3 \mathrm{ml}$. of concentrated ammonium hydroxide and heat the solution with stirring until the precipitate dissolves. Dilute to $200 \mathrm{ml}$. with distilled water.

5\% TIOA-Xylene. Dissolve $5 \mathrm{gm}$. of triisooctylamine and dilute to 100 ml. with xylene. 


\section{$\underline{\text { Procedure }}$}

1. To an appropriate aliquot of the sample solution $(0.5 \mathrm{ml}$.) add 5 $\mathrm{ml}$. of the basic aluminum nitrate reagent.

2. Add $5 \mathrm{ml}$. of $5 \%$ TIOA-xylene solution.

3. Extract for $10 \mathrm{~min}$, and allow the phases to separate.

4. Centrifuge for one minute, if necessary.

5. Pipet an appropriate aliquot $(0.2 \mathrm{ml}$.) of the organic phase on a stainless steel plate. Carefully evaporate to dryness on a hot plate.

6. Flame to a dull red heat, cool, and count the plate in an alpha counter or in s suitable alpha energy analyzer.

\section{PROCEDURE 3}

Extraction-Colorimetric Determination of Thorium Source: Wilson, G. R., ORNL-2866, 82 (Feb. 11, 1960).

Thorium can be quantitatively extracted from $14 \mathrm{~N} \mathrm{HNO}_{3}, 12 \mathrm{~N} \mathrm{HCl,} \mathrm{a}$ mixture of $6 \mathrm{~N} \mathrm{HCl}$ and $6 \mathrm{~N} \mathrm{HNO}_{3}, 5 \mathrm{~N} \mathrm{H}_{3} \mathrm{PO}_{4}$ (containing sufficient $\mathrm{HNO}_{3}$ to keep the thorium in solution) and $10 \mathrm{~N} \mathrm{H}_{2} \mathrm{SO}_{4}$. Thorium can be extracted from higher concentrations of $\mathrm{H}_{2} \mathrm{SO}_{4}$ if the salting agent which is $\mathrm{I} \underline{\mathrm{N}}$ acid deficient is adjusted so that the aqueous before extraction is neutral or acid deficient. After stripping the thorium from the organic phase, it is determined spectrophotometrically by the Thoron procedure.

\section{Reagents}

Acid Deficient $\mathrm{Al}\left(\mathrm{NO}_{3}\right)_{3}$. Dissolve 187 grams of $\mathrm{Al}\left(\mathrm{NO}_{3}\right)_{3} \cdot 9 \mathrm{H}_{2} \mathrm{O}$ in 70 $\mathrm{ml}$ of $\mathrm{H}_{2} \mathrm{O}$. Cool and add $13.3 \mathrm{ml}$. of conc. $\mathrm{NH}_{4} \mathrm{OH}$, heat until in solution and then dilute to $200 \mathrm{ml}$.

TIOA-5\% in Xylene. Take $5 \mathrm{ml}$. of triisooctylamine and dilute to 100 ml with xylene.

$5 \%$ Hydroxylamine Hydrochloride. 


\section{Procedure}

1. Pipet a suitable aliquot containing 20-50 gamma of Th into $5 \mathrm{ml}$. of $\mathrm{Al}\left(\mathrm{NO}_{3}\right)_{3}$ reagent solution in an extraction vessel. Mix well.

2. Add 5 drops of $5 \% \mathrm{NH}_{2} \mathrm{OH} \cdot \mathrm{HCl}$ solution and mix well.

3. Add $5 \mathrm{ml}$. of $5 \%$ TIOA-xylene solution.

1. lixtract for b min.

5. Drain and discard the aqueous phase.

6. Scrub the organic phase with $5 \mathrm{ml}$. of $\mathrm{Al}\left(\mathrm{NO}_{3}\right)_{3}$ solution. Discard aqueous phase.

7. Strip the thorium from the organic phase with two 3-ml. portions

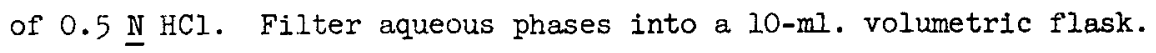

8. Determine the thorium by the spectrophotometric Thoron procedure.

\section{PROCEDURE 4}

\section{Extraction of Uranium From Sulfate Solution}

Source: Crouse, D. J. and Brown, K. B., ORNL-1959 (Sept. 30, 1955).

A one-half volume portion of $0.1 \underline{M}$ tri-n-octylamine in kerosene containing $2 \%$ capryl alcohol will extract uranium(VI) essentially quantitatively from an aqueous sulfate solution adjusted to a pH of 0.85 by mixing for one minute. Fluoride ion does not interfere if sufficient aluminum is present. Iron, aluminum, alkalies, alkaline earths and lanthanides are essentially inextractable under these conditions. Molybdenum(VI) extracts and vanadium(V) extracts if molybdenum(VI) is present. Nitrates and, to a lesser extent, chlorides interfere with the uranyl extraction. The uranium may be stripped from the organic phase with 1 M $\mathrm{Na}_{2} \mathrm{CO}_{3}, 1 \mathrm{M} \mathrm{NaCl}$, or $0.2 \mathrm{M}_{-} \mathrm{HNO}_{3}$. 


\section{PROCEDURE 5}

\section{Determination of Uranium-235 Abundance by Gamma Spectrometry}

Source: Reynolds, S. A. and Eldridge, J. S., ORNL Report CF-57-1-3, Jan. 3, 1957.

\section{Procedure}

1. Make the sample ( $100 \mathrm{mg}$. U) $8 \mathrm{M}$ in $\mathrm{HCl}$ with a total volume of $30 \mathrm{ml}$.

2. Extract with $30 \mathrm{ml}$. of $8 \%(\mathrm{w} / \mathrm{v})$ of tribenzylamine-chloroform for 10 minutes.

3. Reextract the aqueous phase with $20 \mathrm{ml}$. of $8 \% \mathrm{TBA}^{\mathrm{CHCl}} \mathrm{CHCl}_{3}$. Discard the aqueous phase.

4. Combine the extracts and wash with $20 \mathrm{ml}$. of concentrated $\mathrm{HCl}$. Discard the aqueous wash solution.

5. Strip the uranium from the organic phase with $40 \mathrm{ml}$. of distilled water. Discard the organic phase.

6. Wash the aqueous strip solution with $20 \mathrm{ml}$. of $\mathrm{CHCl}_{3}$ to remove any dissolved TBA. Discard the chloroform phase.

7. Add $1 \mathrm{ml}$. of $\mathrm{I} \mathrm{M} \mathrm{HNO}_{3}$ and precipitate ammonium diuranate by adding concentrated $\mathrm{NH}_{4} \mathrm{OH}$.

8. Centrifuge and discard the supernatant liquid.

9. Wash the precipitate with hot water containing $0.3 \% \mathrm{NH}_{4} \mathrm{NO}_{3}$.

10. Transfer the precipitate to a crucible and 1gnite at $900^{\circ} \mathrm{C}$. for one hour. The product is greenish-black $\mathrm{U}_{3} \mathrm{O}_{8}$. Yields average 90-95\%.

11. Place the weighed oxide in a $2 \mathrm{ml}$. volumetric flask and dissolve in 1:1 $\mathrm{HNO}_{3}$ containing 2-3 drops of concentrated $\mathrm{HCl}$. Dilute to the mark with distllled water and $\operatorname{mix}$ well.

12. Pipet $1 \mathrm{ml}$. into a $10 \times 75 \mathrm{~mm}$, culture tube and measure the $0.184-$ Mev. gamma photons by use of a gamma scintillation spectrometer. (91) 


\section{PROCEDURE 6}

\section{Separation of Uranium from Thorium, Fission Products}

and Other Elements in Hydrochloric Acid Solution

Source: Moore, F. L., Anal. Chem. 30, 908 (1958).

A solution of uranium and fission products is adjusted to a hydrochloric acid concentration of $5 \underline{M}$. Anions other than chlorlde should be eliminated by appropriate means. The aqueous solution is extracted for one-half minute with an equal volume portion of $5 \%$ triisooctylamine-xylene. After separation of the phases, the organic phase is washed twice for one-half minute with equal volume portions of $5 \underline{\mathrm{M} \mathrm{HCl}}$. The uranium is then stripped from the organic phase by mixing well for 2 minutes with an equal volume portion of $0.1 \mathrm{M} H \mathrm{HCl}$. The uranium in the strippant solution is then determined by any suitable procedure.

\section{Remarks}

The plutonyl ion behaves like the uranyl ion and may be extracted with the uranium as previously described ${ }^{(29)}$ or rendered in extractable by reduction to the trivalent state.

The procedure has been found to give typical uranium decontamination and recovery data shown in Table XV. (92) Niobium is the limiting fission

Table XV

Recovery and Decontamination of Uranium With 5\% Triisooctylamine-Xylene

\begin{tabular}{lr}
\hline Aqueous Solution & $\begin{array}{r}\text { Per Cent } \\
\text { in Uranium }\end{array}$ \\
\hline Gross $\gamma-1.3 \times 10^{\prime} \mathrm{c} / \mathrm{m}$ & 0.5 \\
$\mathrm{Zr}, \gamma-4.0 \times 10^{5} \mathrm{c} / \mathrm{m}$ & 1.1 \\
$\mathrm{Nb}, \gamma-5.5 \times 10^{5} \mathrm{c} / \mathrm{m}$ & 11.0 \\
Total Lanthanides, $\gamma-1.3 \times 10^{5} \mathrm{c} / \mathrm{m}$ & $<0.1$ \\
Cs, $\gamma-1.2 \times 10^{5} \mathrm{c} / \mathrm{m}$ & $<0.7$ \\
Ru, $\gamma-1.8 \times 10^{5} \mathrm{c} / \mathrm{m}$ & $<0.3$ \\
Sr, $\gamma-7.3 \times 10^{5} \mathrm{c} / \mathrm{m}$ & $<0.2$ \\
Uranium $-10 \mathrm{mg}$. & 98.5 \\
Zirconium - $1.2 \mathrm{mg}$. & --
\end{tabular}


PROCEDURE 6 (Continued)

product contaminant, which can be minimized by performing the extraction from $4 \underline{M} \mathrm{HCl}$. This gives $>95 \%$ extraction of uranium with $<3 \%$ niobium per cycle. The above data are for one cycle, and, obviously, one may improve the purity of the uranium by employing additional scrubs or cycles.

Inasmuch as thorium is essentially inextractable from all concentrations of hydrochloric acid, this system also provides a rapid method for the preparation of $\mathrm{UX}_{1}\left(\mathrm{Th}_{\mathrm{h}}-234\right)$ tracer from its parent U-238.

\section{PROCEDURE 7}

Separation of Uranium From Diverse Ions

Source: Maeck, W. J., Booman, G. L., Elliot, M. C. and Rein, J. E., Anal. Chem. 30, 1902 (1958).

\section{Abstract}

A liquid-liquid extraction procedure for the separation of greater than 99.8\% of uranium(VI) from complex mixtures with one-batch contact is described. It is based on the extraction of tetrapropylammonium uranyl trinitrate with methyl isobutyl ketone from an acid-deficient aluminum nitrate solution. Because 1-year-cooled fission products extract less than $1 \%$, this procedure is especially suitable for separation of uranium from reactor fuel element reprocessing solutions prior to its analytical determination. Per cent extraction for 49 cations at mole ratios of 10 to 1,1 to 1 , and 0.1 to 1 to urabium have been determined. The effects of 30 anions on the extraction of both uranium and fission products have been established.

\section{Apparatus}

Extractions were made in glass test tubes, $15 \times 125 \mathrm{~mm}$., with polyethylene stoppers. The mixing device, patterned after that of Achey, ${ }^{(93)}$ was a $10-$ inch diameter Lucite disk, with six spring clamps for test tubes, mounted on a steel angle iron frame and driven by a 33-r.p.m. motor. Vigorous shaking is not recommended because of possible emulsion formation. 


\section{Reagents}

Reagent grade inorganic chemicals and Eastman Kodak Co., White Label organic chemicals were used without purification. Distilled water was used throughout. The uranium solutions were prepared by dissolving purified black oxide, $\mathrm{U}_{3} \mathrm{O}_{8}$, in a slight excess of nitric acid and making up to volume with water.

The aluminum nitrate salting solution was prepared as follows: Place 1050 grams of aluminum nitrate nonahydrate in a 2-liter beaker and add water to a volume of $900 \mathrm{ml}$. Warm on a hot plate. After dissolution, add 67.5 ml. of concentrated $(14.8 \mathrm{~N})$ ammonium hydroxide, and stir for several minutes until the hydroxide precipitate dissolves. Cool to less than $50^{\circ} \mathrm{C}$. Add $10 \mathrm{ml}$ of $10 \%$ tetrapropylammonium hydroxide reagent and stir until dissolution is complete. Transfer to a l-liter volumetric flask and dilute to volume with water. If this solution is to be used in a method for determining microgram amounts of uranium, a preliminary extraction with methyl isobutyl ketone is suggested to remove uranium contamination. Tetrapropylammonium hydroxide will have to be readded.

\section{Procedure}

Aqueous samples containing up to $2 \mathrm{mg}$. of uranium and as much as $8 \mathrm{M}$ in acid can be quantitatively extracted with a salting solution containing $0.1 \%$ tetrapropylammonium nitrate. Samples of higher acidity should be neutralized to less than $8 \underline{\mathrm{M}}$ acid before extraction. The extraction of larger amounts of uranium is feasible provided the salting solution contains proportionately larger amounts of tetrapropylammonium nitrate.

Pipet a $0.500-\mathrm{ml}$. sample into a test tube containing $4.0 \mathrm{ml}$. of salting solution. Add $2 \mathrm{ml}$. of methyl isobutyl ketone, stopper the tube, and extract for 3 minutes. Centrifuge to facilitate phase separation. An aliquot of the organic phase may be removed and the uranium determined by any suitable procedure. If uranium in lower valence states thar sexivalent is suspected, 


\section{PROCEDURE 7 (Continued)}

boil the sample with sufficient nitric acid before sampling to oxidize uranium to the latter valence state.

\section{Remarks}

The authors have also used the above technique as a basis for the spectrophotometric determination of microgram or milligram amounts of uranium. (71)

\section{PROCEDURE 8}

Radiochemical Determination of Uranium-237

Source: Moore, F. L. and Reynolds, S. A., Anal. Chem., 31, 1080 (1959).

\section{Abstract}

A radiochemical method for the determination of uranium-237 is based on complexing the uranyl ion in alkaline solution with hydroxylamine hydrochloride, followed by scavenging with zirconium hydroxide and extraction of the uranium from hydrochloric acid solution with triisooctylamine-xylene. The technique has been applied successfully to the determination of uranium237 in homogeneous reactor fuel solutions.

\section{Preparation and Standardization of Uranium Carrier}

Weigh out approximately 50 grams of uranyl nitrate hexahydrate. Dissolve and make to $I$ liter with $2 M$ nitric acid. Standardize the carrier by pipetting $5-\mathrm{ml}$. aliquots into $50-\mathrm{ml}$. glass centrifuge cones and precipitating ammonium diuranate by adding concentrated ammonium hydroxide (carbonate free). Filter quantitatively through No. 42 whatman filter paper and ignite in porcelain crucibles at $800^{\circ} \mathrm{C}$. for 30 minutes. Weigh as $\mathrm{U}_{3} \mathrm{O}_{8}$.

\section{Procedure}

In a 40-ml. tapered centrifuge tube add $1 \mathrm{ml}$. of uranium carrier and $0.2 \mathrm{ml}$. of zirconium carrier (approximately $10 \mathrm{mg}$. per $\mathrm{ml}$. of zirconium) to a suitable aliquot of the sample solution. Dilute to approximately $10 \mathrm{ml}$., mix well, and precipitate ammonium diuranate by the addition of concentrated 
ammonium hydroxide. Centrifuge for 2 minutes and discard the supernatant solution. Wash the precipitate once with $15 \mathrm{ml}$. of ammonium hydroxide (1 to 1).

Dissolve the precipitate in 1 to $2 \mathrm{ml}$. of concentrated hydrochloric acid solution, dilute to about $10 \mathrm{ml}$, add $1 \mathrm{ml}$. of hydroxylamine hydrochloride $(5 \mathrm{M})$, and $\operatorname{mix}$ well. Precipltate zirconium hydroxide by the addition of concentrated ammonium hydroxide. Centrifuge for 2 minutes, add $0.2 \mathrm{ml}$. of zirconium carrier, and stir the supernatant solution, being careful not to disturb the precipitate. Centrifuge for 2 minutes. Add $0.2 \mathrm{ml}$. of zirconium carrier and repeat.

Transfer the supernatant solution to another 40-ml. centrifuge tube, add several drops of phenolphthalein, and adjust the pH to approximately 8 by adding concentrated hydrochloric acid solution dropwise. Add an equal volume of concentrated hydrochloric acid solution and extract for approximately 0.5 minute with a one-half volume portion of $5 \%(w . / v$.$) triisooctylamine-$ xylene. Discard the aqueous phase. Wash the organic phase by mixing for 0.5 minute with an equal volume portion of $5 \underline{M}$ hydrochloric acid solution. Repeat the wash step. Strip the uranium from the organic phase by mixing thoroughly with an equal volume portion of $0.1 \underline{M}$ hydrochloric acid solution for 0.5 minute. Discard the organic phase.

Add $0.2 \mathrm{ml}$. of zirconium carrier, $\mathrm{mix}$ well, and repeat the above procedure, beginning with the precipitation of amonium diuranate.

Finally, precipitate ammonium diuranate by the addition of concentrated ammonium hydroxide. Centrifuge for 2 minutes. Decant and discard the supernatant solution. Filter on No. 42 whatman filter paper and ignite at $800^{\circ} \mathrm{C}$. for 30 minutes.

Weigh the uranium oxide on a tared aluminum foil (0.0009 inch), fold, and place in a $10 \times 75 \mathrm{~mm}$. culture tube. Insert a suitable cork and count the uranium-237 gamma radioactivity in a well-type scintillation counter. 
Count the same day of the last chemical separation.

Apply a blank correction if very low uranium-237 levels are being determined. Determine this correction by taking the same aliquot of uranium carrier through the exact procedure described above. The blank correction is due primarily to the gamma radioactivity associated with the uranium-235 in the uranium carrier.

\section{PROCEDURE 9}

Determination of Uranium in Dissolver Solutions By Extraction-Controlled-Potential Coulometric Titration

Source: Shults, W. D., Hobbs, B. B., Blevins, E. L., and Thomason, P. F., ORNL-2776, Sept. 14, 1959.

\section{Reagents}

Aluminum nitrate salting agent - $2.5 \mathrm{M} \mathrm{Al}\left(\mathrm{NO}_{3}\right)_{3}$ made $1.5 \mathrm{M}$ in $\mathrm{NH}_{4} \mathrm{OH}$. Organic Extractant - 5\% (w./v.) triisooctylamine in xylene. Hydroxylamine Hydrochloride - 5\% (w./v.) in water.

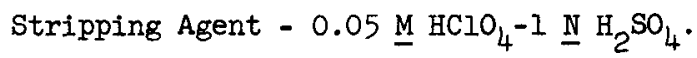

\section{Procedure}

An aliquot of sample containing $5-10 \mathrm{mg}$. of uranium is added to $5 \mathrm{ml}$. of the $\mathrm{Al}\left(\mathrm{NO}_{3}\right)_{3}$ salting agent. The solution is stirred and 5 drops of $\mathrm{NH}_{2} \mathrm{OH}$. $\mathrm{HCl}$ are added. Five $\mathrm{ml}$. of the organic solvent are added and the solution extracted for 5 minutes. After the phases separate, the aqueous phase is drained and discarded. The organic phase is equilibrated twice with $5 \mathrm{ml}$. portions of the stripping reagent, each is drained directly into the coulometric cell. Six drops of concentrated $\mathrm{H}_{2} \mathrm{SO}_{4}$ are added to the solution, mercury is added, and the sample is de-aerated for 5 minutes. The sample is then pre-titrated at $+0.125 \mathrm{v}$. vs. $\mathrm{Ag}-\mathrm{AgCl}$-saturated $\mathrm{KCl}$. Uranium is then titrated at $-0.30 \mathrm{v}$. vs. $\mathrm{Ag}-\mathrm{AgCl}$-saturated $\mathrm{KCl}$. 


\section{$\underline{\text { Remarks }}$}

1. Iron, chromium, and silica are the most serious interferences in stainless steel type dissolver solutions. By the addition of hydroxylamine to the aqueous phase, chromium is rendered inextractable. Iron is partially extracted and is carried over into the coulometric cell. The small amount of iron extracted is pre-reduced at +0.125 volt which reduces iron to its lower valence state and thus prevents its interference in the uranium titration. Silica can be removed by high speed centrifugation.

2. Thorium will extract with the uranium, and care must be exercised to prevent overloading the extractant. For instance, in aliquots containing 2-5 mg. of uranium and 50-60 mg. thorium, a $20 \%(\mathrm{v} . / \mathrm{v}$.$) solution of trilso-$ octylamine in xylene was found satisfactory. In this case, it was necessary to use a stripping reagent of $1 \mathrm{~N} \mathrm{H}_{2} \mathrm{SO}_{4}$ containing $0.2 \mathrm{M} \mathrm{HClO}_{4}$.

3. The method is capable of high accuracy and precision (0.2\%).

\section{PROCEDURE 10}

Separation of Uranium From Thorium, Fission Products and Other Elements in Acetic Acid Solution

Source: Moore, F. L., Anal. Chem. 32, 1075 (1960)

Uranium readily extracts from dilute acetic acid solutions or dilute acetic acid - dilute nitric acid solutions with triisooctylamine dissolved in xylene or other solvents. Excellent separation of uranium is effected from thorium, alkalies, alkaline earths, trivalent lanthanides and actinides and many other metals. However, zirconium, niobium and ruthenium extract in varying amounts (Tables XVI, XVII) and it is necessary to remove these elements by scrubbing the organic phase with $5 \mathrm{M} \mathrm{HCl}$. A preliminary hydroxide precipitation followed by extraction of uraniun from 1 M acetic acid solution achieves higher selectivity and is recommended to the separations chemist. Several procedures have been tested for the extraction and decontamination of 
uranium in acetic acid solution. The data reported here refer strictly to the acetic acid or dilute nitric acid-acetic acid systems. The presence of other anions may change the extraction characteristics. After the described pretreatment a standard extraction procedure was applied as follows:

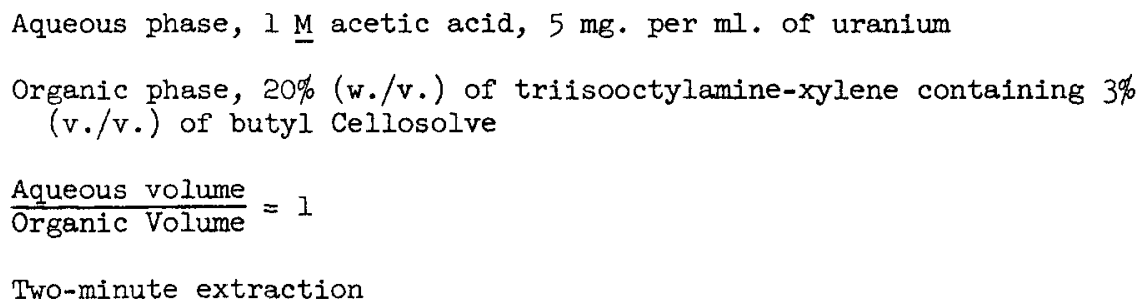

Procedures

A. (1) Direct Extraction of Uranium from Acetic Acid Solution. Tracer solutions of the major fission products were prepared in $I \underline{M}$ acetic acid solution and extracted according to the standard extraction procedure. Typical results are shown in Table XVI. Uranium recoveries averaged 98 to

Table XVI

Direct Extraction of Fission Products from $1 M$ Acetic Acid Solution

\begin{tabular}{lc}
\hline Element & $\begin{array}{c}\text { Tracer } \\
\text { Extracted, \% }\end{array}$ \\
\hline $\mathrm{Cs}^{137}$ & $<0.001$ \\
$\mathrm{Sr}^{85}$ & $<0.001$ \\
$\mathrm{Eu}^{152}$ & $<0.001$ \\
$\mathrm{Ru}^{106}$ & 11.5 \\
$\mathrm{Zr}^{95}$ & 27.9 \\
$\mathrm{Nb}^{95}$ & 11.1
\end{tabular}

99\%. Scrubbing the organic phase with various solutions could be used to achieve further decontamination of the uranium. However, no additional work was done in this respect, because one rarely w1ll be dealing with a pure acetic acid solution of uranium or plutonium. 
(2) Direct Extraction of Uranium from Nitric Acid-Acetic Ac1d Mixtures. Uranium is ordinarily dissolved in nitric acid solution, and the feasibility of utilizing the uranyl acetate extraction from dilute nitric acid was investigated. Table XVII shows the recovery of uranium from $I \underline{M}$ acetic acid containing dilute nitric acid. Standard extraction conditions were used with the exception of the nitric acid addition. Thus, one can effect an excellent recovery of uranium from dilute nitric acid-acetic acid solutions.

Table XVII

Direct Extraction of Uranium from Dilute Nitric Acid-Acetic Acid Solutions

\begin{tabular}{ccc}
\hline $\begin{array}{c}\text { Aqueous } \\
\text { Phase, }\end{array}$ & $\begin{array}{c}\text { No. of } \\
\text { Extractions }\end{array}, \mathrm{M}$ & $\begin{array}{c}\text { Uranium } \\
\text { Extracted, } \\
\%\end{array}$ \\
\hline 0.5 & 1 & 86.5 \\
0.5 & 2 & 99.4 \\
0.1 & 1 & 97.3 \\
0.1 & 2 & 99.7 \\
\hline$+1 \mathrm{M} \mathrm{CH}_{3} \mathrm{COOH}$. & &
\end{tabular}

The nitric acid present prevents the formation of anionic uranyl acetate but, upon mixing, the tertiary amine extracts the nitric acid, thereby allowing the formation and extraction of anionic uranyl acetate. Nitric acid concentrations greater than $0.5 \mathrm{M}$ were not investigated because, once the solvent is saturated with nitric acid, the aqueous nitric acid concentration would be high enough to prevent the formation of the extractable anionic uranyl acetate. Also, the selectivity of the acetate system would be lost, inasmuch as some elements form extractable anionic nitrate species in this system. Table XVIII indicates typical data. Cesium, strontium, and europium do not extract. The extraction of ruthenium, zirconium, and niobium was variable (10 to 50\%). These elements may be removed effectively from the uranium by 


\section{PROCEDURE 10 (Continued)}

scrubbing the organic phase with $5 \underline{M}$ hydrochloric acid solution. (29) For instance, when the organic extracts were scrubbed with three equal-volume portions of $5 \underline{M}$ hydrochloric acid solution for 2 minutes each, additional decontamination is achieved (Table XVIII). Loss of uranium from the organic phase under these conditions is negligible. The uranium may be stripped from

\section{Tuble XVIII}

Direct Extraction of Various Elements From 0.1 M Nitric Acid-1 M Acetic Acid Solution

\begin{tabular}{|c|c|c|c|}
\hline \multirow[b]{2}{*}{ Element } & \multicolumn{3}{|c|}{ Tracer Found, $\%$} \\
\hline & $\begin{array}{l}\text { Organic } \\
\text { Phase }\end{array}$ & $\begin{array}{l}\text { Organic Phase After } \\
5 \mathrm{M} \mathrm{HCl} \text { Scrubs }\end{array}$ & $\begin{array}{l}0.1 \mathrm{M} \text { HCl strip- } \\
\text { ping Solution }\end{array}$ \\
\hline $\mathrm{Cs}^{137}$ & $<0.001$ & --- & -- \\
\hline $\mathrm{Sr}^{85}$ & $<0.001$ & -- & -- \\
\hline $\mathrm{Eu}^{152}$ & $<0.001$ & -- & $\cdots$ \\
\hline $\mathrm{Ru}^{106}$ & 10.8 & -- & $<0.1$ \\
\hline $\mathrm{Zr}^{95}$ & 47.0 & -- & $<0.3$ \\
\hline $\mathrm{Nb}^{95}$ & 33.9 & 5.7 & 3.2 \\
\hline $\mathrm{Th}^{230}$ & $<0.1$ & --- & --- \\
\hline $\mathrm{Fe}^{59}$ & $<0.05$ & -- & --- \\
\hline
\end{tabular}

the organic phase by mixing well with a double-volume portion of 0.1 M hydrochloric acid solution. Approximately $85 \%$ recovery of the uranium is possible using this procedure. A second stripping step removes the remaining uranium from the organic phase. Decontamination was found to be slightly better, using macro amounts of uranium in all cases.

(B) Fydroxide Precipitation Followed by Extraction from Acetic Acid Solution.

Acetic acid solutions of uranium and plutonium are not ordinarily encountered, and it is usually necessary to perform a hydroxide precipitation followed by dissolution in acetic acid to secure a solution suitable for extraction. Two carriers have been studied in this respect. 
(1) Iron Hydroxide. Because iron is a common impurity in solutions of uranium and plutonium and does not extract in the acetic acid-triisooctylamine system, experiments were performed using iron hydroxide to carry uranium. If macro amounts of uranium are used, the addition of iron is not necessary. One simply precipitates ammonium diuranate; however, the presence of iron has no detrimental effect.

Table XIX

Extraction of Various Elements from I M Acetic Acid Solution After Iron Hydroxide Precípitation

\begin{tabular}{|c|c|c|c|}
\hline & \multicolumn{3}{|c|}{ Tracer Found, \% } \\
\hline & $\begin{array}{c}\text { Organic } \\
\text { Phase }\end{array}$ & $\begin{array}{l}\text { After } 5 \mathrm{M} \\
\mathrm{HCl} \text { Scrub }\end{array}$ & $\begin{array}{l}0.1 \mathrm{M} \text { HCl'strip- } \\
\text { ping Solution }\end{array}$ \\
\hline $\mathrm{Cs}^{137}$ & $<0.001$ & & \\
\hline $\mathrm{Sr}^{85}$ & $<0.001$ & & \\
\hline $\mathrm{Eu}^{152}$ & $<0.001$ & & \\
\hline $\mathrm{Ru}^{106}$ & 4.9 & 4.9 & $<0.1$ \\
\hline $\mathrm{Zr}^{95}$ & 1.9 & 0.2 & $<0.05$ \\
\hline $\mathrm{Nb}^{95}$ & 0.4 & 0.07 & $<0.02$ \\
\hline $\operatorname{Th}^{230}$ & $<0.1$ & -- & --- \\
\hline $\mathrm{Fe}^{59}$ & 0.02 & $\cdots$ & -- \\
\hline $\mathrm{Pa}^{233}$ & 0.3 & --- & -- \\
\hline $\mathrm{Am}^{241}$ & $<0.01$ & -- & -- \\
\hline
\end{tabular}

A dilute nitric acid solution containing $20 \mathrm{mg}$. of ferric iron, $50 \mathrm{mg}$. of uranium(VI), and various tracers was diluted to approximately $15 \mathrm{ml}$. with distilled water. After thorough mixing, an excess of concentrated ammonium hydroxide (carbonate-free) was added. After centrifugation in a clinical centrifuge for 3 minutes, the supernatant solution was discarded and the precipitate was washed well with approximately $20 \mathrm{ml}$. of distilled water. The solution was centrifuged for 3 minutes, the supernatant solution decanted, 
and the hydroxide precipitate dissolved in $10 \mathrm{ml}$. of $1 \mathrm{M}$ acetic acid solution. The standard extraction procedure was then performed on this solution. Table XIX indicates typical decontamination data. Uranium extractions averaged approximately $98 \%$. In some cases, the decontamination was improved further by scrubbing the organic phase for 2 minutes with an equal-volume portion of $5 \underline{M}$ hydrochloric acid solution followed by a double-volume portion of $0.1 \mathrm{M}$ hydrochloric acid stripping solution for 2 minutes.

(2) Niobium Pentoxide. Freshly-precipitated niobium pentoxide is essentially insoluble in acetic acid. The experiments described above using iron hydroxide as carrier were repeated with the addition of $12 \mathrm{mg}$. of niobium carrier. The iron and uranium were leached from the precipitate with $10 \mathrm{ml}$. of I $M$ acetic acid solution by thoroughly mixing with a curved stirring rod. The leach solution was decanted and extracted according to the standard extraction procedure. Filtering the acetic acid leach solution through No. 40 Whatman filter paper gave slightly better decontamination. Uranium recoveries averaged 70 to $85 \%$. Additional leaching of the hydroxide precipitate with $1 \mathrm{M}$ acetic acid solution may be used to recover more uranium. Table XX indicates typical decontamination data found using this procedure.

Table XX

Extraction of Various Elements from $1 \mathrm{M}$ Acetic Acid Leach Solution After Niobium Pentoxide P̄recipitation

\begin{tabular}{lc}
\hline Element & $\begin{array}{c}\text { Tracer } \\
\text { Extracted, }\end{array}$ \\
\hline $\mathrm{Cs}^{137}$ & $<0.001$ \\
$\mathrm{Sr}^{85}$ & $<0.001$ \\
$\mathrm{Eu}^{152}$ & $<0.001$ \\
$\mathrm{Ru}^{106}$ & 0.4 \\
$\mathrm{Zr}^{95}$ & 0.05 \\
$\mathrm{Nb}^{95}$ & $<0.001$
\end{tabular}


No attempts were made to increase the decontamination by scrubbing techniques; this could be done by using $5 \underline{M}$ hydrochloric acid scrubs as described under Iron Hydroxide above.

\section{Remarks}

The extraction behavior of the plutonyl ion is similar to that of the uranyl ion in this system. It may be extracted with the uranium when present as $\mathrm{PuO}_{2}^{++(67)}$ or rendered inextractable by reduction to the trivalent state.

PROCEDURE 21

Purification of Uranium for Mass Spectrometry

Source: Webster, R. K., Dance, D. F., Morgan, J. W., Preece, E. R., Slee, I. J. and Smales, A. A., Analytica Chimica Acta 23, 101 (Aug. 1960).

\section{Procedure}

1. To a $5 \underline{\mathrm{M}} \mathrm{HCl}$ solution (1-3 $\mathrm{ml}$.) containing the uranium, add 2 drops of bromine water and $I \mathrm{ml}$. of $5 \%(\mathrm{v} . / \mathrm{v}$.$) trisooctylamine-xylene. Mix,$ centrifuge, separate.

2. Repeat step 1.

3. Add $0.5 \mathrm{ml}$. of xylene. Mix, centrifuge, separate.

4. To the combined xylene fractions, add $1 \mathrm{ml}$. of water. Mix, centrifuge, separate.

5. Repeat step 4.

6. To the combined water fractions add $1 \mathrm{ml}$. of xylene. Mix, centrifuge, separate.

7. Repeat step 6.

8. Evaporate the water solution to dryness in a small platinum dish and destroy the organic matter by oxidation with nitric and perchloric acids.

9. Add a little nitric acid to the platinum dish, evaporate to a small 
volume, transfer to a glass plate and evaporate to dryness. Repeat this process 2 or 3 times.

10. Dissolve the deposit of uranium in a drop of water and transfer to a mass spectrometer filament.

\section{Remarks}

1. Chemical yield is at least $90 \%$.

2. The product water stripping solution contains $1-2 \%$ of the original $\beta, \gamma$ radioactivity based on a 150 -day "cooling" period.

\section{PROCEDURE 12}

Determination of Radiozinc

Source: Ieddicotte, G. W. and Mahlman, H. A. (to be published in ORNL Master Analytical Manual).

1. To an acid solution add $1 \mathrm{ml}$. of zinc carrier $(20 \mathrm{mg} / \mathrm{ml})$ and $10 \mathrm{mg}$. each of the holdback carriers, $\mathrm{Fe}, \mathrm{Co}, \mathrm{Cu}, \mathrm{Sr}$, and $\mathrm{Na}$.

2. Make $\sim 1 \mathrm{~N} \mathrm{HCl}$ and saturate with $\mathrm{H}_{2} \mathrm{~S}$.

3. Boil supernatant solution with $\mathrm{HNO}_{3}$ and bromine water.

4. Add concentrated $\mathrm{NH}_{4} \mathrm{OH}$ to precipitate $\mathrm{Fe}(\mathrm{OH})_{3}$. Centrifuge and save the supernatant solution.

5. Saturate supernatant solution with $\mathrm{H}_{2} \mathrm{~S}$. Centrifuge and discard supernatant solution.

6. Dissolve the precipitate with $\mathrm{HNO}_{3}$ and bromine water.

7. Evaporate to near dryness and add $\mathrm{HCl}$. Continue adding $\mathrm{HCl}$ to remove $\mathrm{HNO}_{3}$.

8. Take up in $5 \mathrm{ml}$. of $3 \underline{\mathrm{N}} \mathrm{HCl}$.

9. Extract the zinc into a double volume portion of $8 \%$ tri-n-benzylamine-chloroform. Reextract the aqueous phase once. Combine organic phases.

10. Wash the organic phase with $10 \mathrm{ml}$. of $3 \underline{\mathrm{N}} \mathrm{HCl}$.

11. Strip the zinc into $10 \mathrm{ml}$. of $0.1 \mathrm{~N} \mathrm{HCl}$. 
12. Adjust the acidity of the strip solution to $1 \mathrm{~N} \mathrm{HCl}$ and add $10 \mathrm{ml}$. of zinc reagent. ${ }^{*}$ Cool in an ice bath and stir to precipitate $\mathrm{ZnHg}(\mathrm{SCN})_{2}$.

13. Filter through \#42 Whatman filter paper. Wash with water and alcohol. Dry in oven at $105^{\circ} \mathrm{C}$. Mount the precipitate and count.

\section{PROCEDURE 13}

Extraction-Colorimetric Determination of Zinc

Source: Scroggie, L. E. and Dean, J. A., Analytica Chimica Acta 21, 282 (Sept. 1959).

\section{Summary}

A study was made of the extraction of zinc from hydrochloric acid solutions with solutions of methyldioctylamine and triisooctylamine in methyl isobutyl ketone. Quantitative extraction was accomplished from $2 \underline{\mathrm{N}}$ hydrochloric acid with $5 \%$ (w./v.) trilsooctylamine-methyl isobutyl ketone. A procedure was developed for the colorimetric determination of zinc in the organic phase after extraction using 2-carboxy-2-hydroxy-5'-sulfoformazylbenzene (Zincon).

\section{Apparatus and Reagents}

Spectrophotometer and Colorimeter. Prellminary studies were done using a Beckman Model DU quartz spectrophotometer employing l-cm, corex-glass, absorption cells. A Bausch and Lomb Spectronic 20 colorimeter with one-half inch $(1.33 \mathrm{~cm})$ cylindrical cells was used for subsequent work.

Zincon (2-carboxy-2'-hydroxy-5'-sulfoformazylbenzene) Solution. Zincon solutions were prepared by dissolving $0.130 \mathrm{~g}$ of finely powdered Zincon in $2 \mathrm{ml}$. of $I \underline{N}$ sodium hydroxide and diluting to $100 \mathrm{ml}$. with $95 \%$ ethanol. This gives a solution which is $0.002 \underline{\mathrm{M}}$, based on a purity of $68 \%$ for the reagent.

\footnotetext{
* Zinc Reagent: Prepare by dissolving $32 \mathrm{gms}$. of $\mathrm{NH}_{4} \mathrm{SCN}$ and $27 \mathrm{gms}$. of $\mathrm{HgCl}_{2}$ in $500 \mathrm{ml}$. of water. Shake well.
} 
Zincon was obtained from LaMotte Chemical Products Co., Baltimore, Maryland. A fresh solution should be prepared weekly.

Standard Zinc Solutions. A standard zinc solution was prepared by dissolving $0.2500 \mathrm{~g}$. of reagent grade zinc metal in $1 \mathrm{ml}$. of conc. hydrochloric acid and diluting to $250 \mathrm{ml}$. With deionized water. This gives a solution containing $1000 \mu \mathrm{g}$ of zinc per $\mathrm{ml}$. A solution containing $100 \mu \mathrm{g}$. of zinc per $\mathrm{ml}$. was prepared by diluting $10.0 \mathrm{ml}$. of the stock solution to $100 \mathrm{ml}$. with deionized water.

Triisooctylamine-methyl 1sobutyl ketone. A solution containing 5\% (w./v.) trilsooctylamine in methyl isobutyl ketone was prepared. All organic solvents were practical grade and were used without further purification. All agneous solutions were prepared from reagent grade chemicals and using deionized water which was prepared by passing ordinary distilled water through a bed of Amberlite MB-3 ion-exchange resin.

\section{Recommended Procedures}

Calibration Curve. To suitable aliquot portions of a standard zinc solution, add $1.0 \mathrm{ml}$. of $10 \mathrm{~N}$ hydrochloric acid and enough water to give a total volume of $5.0 \mathrm{ml}$. Shake with $10.0 \mathrm{ml}$. of $5 \%$ (w./v.) trilsooctylaminemethyl isobutyl ketone in a 30-ml. separatory funnel for $3 \mathrm{~min}$. Remove and discard the aqueous phase. Dry the stem of the funnel with a strip of filter paper. Drain the ketone layer into a $50-\mathrm{ml}$ volumetric flask. Add $5.0 \mathrm{ml}$. of $1.0 \mathrm{~N}$ potassium hydroxide, $5.0 \mathrm{ml}$. of methyl isobutyl ketone, and $3.0 \mathrm{ml}$. of zincon solution. Dilute to the mark with $95 \%$ ethanol and mix thoroughly. After $8 \mathrm{~min}$. standing, measure the absorbancy at $620 \mathrm{m \mu}$ against a reagent blank. Plot absorbancies against concentration expressed as $\mu \mathrm{g}$ of zinc per $\mathrm{ml}$. Procedure for Magnesium-base Alloys. Dissolve a suitable size sample in dilute hydrochloric acid and dilute to a known volume. Transfer a suitable aliquot portion to a $30 \mathrm{-ml}$ separatory funnel. Add $1.0 \mathrm{ml}$ of $10 \mathrm{~N}$ hydrochloric acid and enough water to give a total volume of $5.0 \mathrm{ml}$. Extract, develop 
the color, and measure as described under Calibration Curve. Determine the zinc concentration from a calibration curve.

Procedure for Aluminum-base Alloys. To the sample add $3 \mathrm{ml}$. of $19 \mathrm{~N}$ sodium hydroxide. After $3 \mathrm{~min}$, add $3 \mathrm{ml}$. of water. After the reaction subsides, heat the solution to boiling and boil for $3 \mathrm{~min}$. Cool to room temperature and acidify with hydrochloric acid. Transfer the solution to a volumetric flask and dilute to a known volume. Transfer a 4.0-ml. aliquot to a 30-ml. separatory funnel and add $1.0 \mathrm{ml}$. of $10 \mathrm{~N}$ hydrochloric acid. Shake for 2 min. with $10.0 \mathrm{ml}$. of $5 \%$ (w./v.) triisooctylamine-methyl isobutyl ketone. Remove and discard the aqueous phase. Wash the ketone layer with a fresh $5.0-\mathrm{ml}$. portion of $2.0 \mathrm{~N}$ hydrochloric acid and discard the aqueous phase. Bask-extract the zinc by shaking the ketone layer for 1 min. with two $5.0-\mathrm{ml}$. portions of $0.05 \mathrm{~N}$ hydrochloric acid. Combine the aqueous phases and transfer a $4.0-\mathrm{ml}$. aliquot to a clean $30-\mathrm{ml}$. separatory funnel. Add 1.0 $\mathrm{ml}$. of $10 \underline{\mathrm{N}}$ hydrochloric acid. Extract for $2 \mathrm{~min}$. with $10.0 \mathrm{ml}$. of $5 \%(\mathrm{w} . / \mathrm{v}$. trilsooctylamine-methyl isobutyl ketone. Remove and discard the aqueous phase. Dry the stem of the funnel with a strip of filter paper. Transfer the ketone layer to a $50-\mathrm{ml}$. volumetric flask. Proceed with the color development and measurement as described under Calibration Curve. Determine the zinc concentration from a calibration curve. 


\section{PROCEDURE 14}

Determination of Microgram Concentrations of Zirconium in Aqueous Solutions Containing Uranium

Source: Laux, P. G. and Brown, E. A., TID-7568 (Pt. 1) p. 135 (Sept. 1958).

\section{Procedure}

Transfer a suitable sample containing 10 to $100 \mu \mathrm{g}$ of zirconium to a 250-ml. beaker. Remove the nitrate (if present) by repeated evaporations to near-dryness with 25-ml. portions of concentrated $\mathrm{HCl}$. (If solid $\mathrm{UO}_{3}$ samples are received, they are first dissolved in $10 \mathrm{ml}$. of $\mathrm{HCl}$ ). Adjust the acidity to $4 \mathrm{M}$ with $\mathrm{HCl}$, and extract the uranium with an equal volume portion of $5 \%$ triisooctylamine-xylene. Discard the organic phase. Repeat the extraction until the aqueous phase is free of uranium. Evaporate the aqueous phase to near-dryness, and determine the zirconium by the Alizarin red $S$ method.

\section{Remarks}

1. The method was found satisfactory using aliquots for analysis containing approximately one gram of uranium.

\section{PROCEDURE 15}

\section{Separation of Zirconium From Titanium and Magnesium With Trifsooctylamine-Xylene. Application to the Analysis of Zirconium Metal Alloys}

Source: Feldman, C. and Pritchard, C. A., ORNL CF-60-11-23.

\section{Introduction}

This procedure has been used for the isolation and determination of titanium and magnesium in zirconium metal alloys spectrographically by the porous cup technique. Hydrogen peroxide effectively prevents titanium from extracting with the zirconium.

When a $10 \underline{\mathrm{N}} \mathrm{HCl}$ solution of zirconium and titanium was mixed by shaking with $20 \%$ triisooctylamine-xylene, ${ }^{(29)}$ approximately $12 \%$ of the titanium was 
lost. With a similar solution which was made $3 \%$ in hydrogen peroxide, approximately $14 \%$ of the titanium was lost. In a solution of $10 \mathrm{~N} \mathrm{HCl}$ and $0.3 \%$ hydrogen peroxide, the loss of titanium was essentially zero.

When a $10 \underline{\mathrm{N}} \mathrm{HCl}$ solution of zirconium and magnesium was equilibrated with triisooctylamine-xylene, little or no magnesium extracted.

\section{A. Reagents}

1. Concentrated $\mathrm{HCl}, \mathrm{HNO}_{3}, \mathrm{H}_{2} \mathrm{SO}_{4}$, and $\mathrm{HF}(48-50 \%)$. Solution of $30 \%$ hydrogen peroxide.

2. Standard stack solutions, $1.00 \%$ cobalt in $\mathrm{HNO}_{3}, 1.00 \%$ zirconium in $\mathrm{HF}$ and $\mathrm{HCl}, 1.00 \%$ titanium in $\mathrm{H}_{2} \mathrm{SO}_{4}$ and $n .3 \%$ hydrogen peroxide, and $1.00 \%$ magnesium in $\mathrm{HCl}$.

3. Solution of $20 \%$ triisooctylamine in xylene. This solution was made by equilibrating an equal volume of $20 \%$ triisooctylamine-xylene and a solution of $10 \mathrm{~N}$ HCl for one minute. The mixture was allowed to separate into layers, and the acid layer was drawn off and discarded. The treatment of the organic layer was repeated twice. This solution must be prepared fresh before using.

\section{B. Metal Alloys of Zirconium}

Metal alloys of zirconium, titanium and magnesium were treated as Pollows :

1. A portion of sample containing 0.100 to 1.000 gram of the metal was weighed out and placed in a platinum dish.

2. Approximately $10 \mathrm{~m}$. of concentrated $\mathrm{HNO}_{3}$ was added. Concentrated HF was added dropwise until all of the sample was in solution. If necessary, more $\mathrm{HNO}_{3}$ was added.

3. Approximately $5 \mathrm{ml}$. of concentrated $\mathrm{H}_{2} \mathrm{SO}_{4}$ was added and the solution was evaporated, first on a steam bath and then on a hot plate until the residue was just slightly moist, not dry. The residue was treated in the same manner as for synthetics beginning with Synthetics Preparation, step 3. 
PROCEDURE 15 (Continued)

Table XXI

Titanium Data

\begin{tabular}{llllllll}
\hline \multicolumn{1}{c}{ Synthetic } & $\mathrm{T}-1$ & $\mathrm{~T}-2$ & $\mathrm{~T}-3$ & $\mathrm{~T}-4$ & $\mathrm{~T}-5$ & $\mathrm{~T}-6$ & $\mathrm{~T}-7$ \\
\hline Zirconium, Added, mg & 100 & 100 & 0.0 & 0.0 & 100 & 100 & 100 \\
Titanium, Added, mg & 1.000 & 0.100 & 0.100 & 0.100 & 0.025 & 0.025 & 0.025 \\
Hydrogen Peroxide added $\%$ & 0.3 & 0.3 & 0.3 & 0.3 & 0.0 & 0.3 & 3.0 \\
Final Volume, ml & 500 & 50 & 50 & 50 & 10 & 10 & 10 \\
Titanium Recovered, mg & 0.965 & 0.103 & 0.101 & 0.097 & 0.0219 & 0.0243 & 0.0217 \\
& 0.998 & 0.103 & & 0.097 & & & \\
Percent (, 0 ) recovered & $* 98$ & $* 103$ & 101 & $* 97$ & 88 & 97 & 86 \\
Loss or Gain $(0,0)$ & \pm 4 & \pm 3 & +1 & \pm 3 & -12 & -3 & -14
\end{tabular}

* Average of duplicates.

\section{Synthetics Preparation}

1. The synthetics were prepared by taking an aliquot from each of the standard stock solutions containing the element in question and placing them in a platinum dish (Note b). The composition of each synthetic is shown in Tables XXI and XXII.

2. In order to get rid of fluoride and other anions which interfere in the extraction, the synthetic was treated in the following manner: About $2 \mathrm{ml}$. of sulfuric acid was added in excess, the dish was placed on a hot plate and the excess sulfuric acid evaporated until the residue was just slightly moist, not dry. If the resldue is allowed to evaporate to dryness, it is more difficult to dissolve in $10 \mathrm{~N} \mathrm{HCl}$ solution.

3. If the synthetic was extracted in the presence of hydrogen peroxide, the residue was dissolved in a solution of $0.3 \%$ hydrogen peroxide and $10 \mathrm{~N}$ HC1. If the synthetic was not extracted in the presence of hydrogen peroxide, the residue was dissolved in $10 \mathrm{~N} \mathrm{HCl}$. Approximately $25 \mathrm{ml}$. of solvent was used per $100 \mathrm{mg}$. of zirconium. 
4. The solution was transferred to a $125 \mathrm{ml}$. separatory funnel and an equal volume of fresh $20 \%$ trilsooctylamine in xylene (Reagent 3) was added. The solutions were mixed by vigorously shaking for one to two minutes.

5. The layers were allowed to separate, centrifuged, and the acid layer was drained off and saved.

6. Steps 4 and 5 were repeated as many times as were necessary. Usually two or three extractions were sufficient (Note c).

7. The aqueous acid layers were combined and transferred to a beaker and evaporated to dryness. A few drops of concentrated $\mathrm{HNO}_{3}$ was added occasionally to help decompose the organic during the evaporation.

8. The aqueous residue was dissolved with a solution of $1 \%_{2} \mathrm{H}_{2} \mathrm{SO}_{4}$ and $0.3 \%$ hydrogen peroxide (Note $d$ ). The solution was transferred to an appropriate flask and a measured quantity of the $1 \%$ cobalt standard stock solution was added to make $25 \mu \mathrm{g} / \mathrm{ml}$. of cobalt internal standard.

9. A blank was run along with the synthetics in order to correct for contamination.

10. The solutions were analyzed spectrographically by the porous cup technique. The results are shown in Tables XXI and XXII.

Table XXII

Magnesium Date (Note e)

\begin{tabular}{llllll}
\hline \multicolumn{1}{c}{ Syncnetic } & M-1 & M-2 & M-3 & M-4 \\
\cline { 1 - 3 } Zirconium, Added, mg & 20 & 100 & 100 & 20 \\
Magnesium, Added, mg & 0.500 & 0.500 & 0.050 & 0.500 \\
Final Volume, ml & 1000 & 1000 & 100 & 1000 \\
Magnestum, Recovered, mg & 0.480 & 0.530 & 0.057 & 0.435 \\
Per cent (\%) recovered & 94 & 106 & 114 & 87 \\
Loww or Gain (\%) & -6 & +6 & +14 & -13
\end{tabular}


PROCEDURE 15 (Continued)

\section{Discussion}

When synthetic solutions of zirconium and titanium were extracted with a mixture of trisooctylamine-xylene and $10 \underline{\mathrm{N}} \mathrm{HCl}$, an appreciable loss of titanium occured. To prevent this loss, hydrogen peroxide was added to the aqueous ac1d solution. Mechanical difficulties developed with $3 \%$ hydrogen peroxide solution due to the formation and discharge of gas from the decomposition of hydrogen peroxide. The gas caused conslderable losses due to leaking of the solution around the stopper and stopcock of the separatory funnel. Favorable mechanical operation was obtained with $0.3 \%$ hydrogen peroxide. Leaking of the solution was avolded by venting the gas occasionally during the equilibration. With $0.3 \%$ hydrogen peroxide present, titanium losses by extraction or otherwise were negligible or less than experimental error.

Magnesium does not extract from 10 N HCl solution into trilsooctylaminexylene. The greatest difficulty with the separation of this element from zirconium is due to mechanical contamination. The number of manipulations necessary for the separation made it difficult to avoid air borne particles containing magnesium. The loss in magnesium in Synthetic $M-1$, and $M-4$, Table XXII, may be due to less contamination in the synthetic than in the blank that was carried along with it. Synthetic $M-2$ recovery of magnesium is barely outside of experimental error. Synthetic M-3 shows that the Synthetic may have picked up more contamination than 1ts blank. The average percent recovery for the four synthetics is $100 \% \pm 14 \%$.

\section{Conclustons}

1. When a $10 \underline{\mathrm{N}} \mathrm{HCl}$ solution of zirconium and titanium sulfate was equilibrated with freshly prepared 20\% trilsooctylamine-xylene, approximately $12 \%$ of of the titanium was lost (Syn. T-5).

2. With a similar solution to that in (1) which was made $3 \%$ in hydrogen peroxide, mechanical losses were $14 \%$ (Syn T-7). 
3. With a similar solution to that in(1) which was made $0.3 \%$ in hydrogen peroxide, the loss was $3 \%$ or within experimental error. (Syn. T-6).

4. Additional data from Table $I$, on Synthetics $T-1, T-2$, and $T-3$ shows that $0.3 \%$ hydrogen peroxide prevented the loss of titanium due to extraction and had a low enough rate of decomposition that losses due to gas pressure leaks could be avoided. The average per cent recovery of titanium for the three synthetics is $100 \pm 4 \%$.

5. Titanium can be separated from zirconium with reasonable ease. The zirconium and titanium sulfate is dissolved in a solution $10 \mathrm{~N} \mathrm{HCl}$ and $0.3 \%$ hydrogen peroxide. The airconium complex is extracted into a freshly prepared solution of $20 \%$ triisooctylamine-xylene, leaving the titanium complex in the aqueous acid.

6. Magnesium can be separated from zirconium by extracting the zirconium complex from a solution of $10 \mathrm{~N} \mathrm{HCl}$ leaving the magnesium in the aqueous acid. Care must be taken in performing the operation to prevent excessive contamination.

\section{Note a}

One extraction was performed according to the above procedure on a solution of $10 \mathrm{~N} \mathrm{HCl}$ and $0.3 \%$ hydrogen peroxide containing $100^{\prime} n_{0}$. of zirconium and $0.200 \mathrm{mg}$. of titanium as sulfates. $0.500 \mathrm{mg}$. of aluminum, $0.200 \mathrm{mg}$. of calcium, $0.500 \mathrm{mg}$. of chromium, and $0.500 \mathrm{mg}$. of nickel as chlorides, 0.500 mg. of manganese and $0.500 \mathrm{mg}$. of copper as nitrates. A spectroscopic, porous cup, visual examination showed that zirconium, copper and manganese extracted into trisooctylamine. Calcium and aluminum appeared to extract to some extent, and titanium, chromium(III), and nickel extracted very little, if at all.

Note $\mathrm{b}$

All solutions containing HF were kept in platinum or polyethylene contalners. Calibrated polyethylene pipets were used where needed. 


\section{PROCEDURE 15 (Continued)}

Note $c$

The progress of the extraction of the zirconium was checked after three equilibrations. Thoron reagent $(90)$ was used for the test in the following manner: Three volumetric flasks of $1 \mathrm{ml}$. volume were labeled 1,2 , and 3 . In each was placed approximately $0.5 \mathrm{ml}$. of water, three drops of $0.3 \%$ Thoron reagent, and one drop of concentrated hydrochloric acid. In addition, a solution containing $5 \mathrm{\mu g}$ of standard zirconium was placed in flask 2, one drop of the aqueous solution to be tested was placed in flask 3 , and each of the three flasks were diluted to volume with water, stoppered, and placed in a hot water bath at approximately $80^{\circ} \mathrm{C}$ for five minutes to develop the color of the zirconium complex. If the color is allowed to develop at room temperature, the time must be increased to two hours. The completeness of the extraction of zirconium was noted by comparing the intensity of color of the solutions in the three flasks. If the color of the solution in flask 3 was 2 cieeper red than that of the solution in flask 2 , then the extraction of the zirconium was not considered to be complete. If the color of the solution in flask 3 were similar to the blank solution in flask 1 , and lighter in color than the solution in flask 2, then the extraction was considered to be complete. Fluoride ion interferes with the extraction and with the test for zirconium. The fluoride ion must be evaporated completely from the sample before the extraction is started. Hot sulfuric acid was used for this purpose.

Note $d$

$0.3 \%$ hydrogen peroxide was added in all cases at this point to complex the titanium.

Note $\mathrm{e}$

These results were corrected for magnesium contamination by subtracting the quantity of magnesium that was found in respective blanks for each synthetic. 


\section{REFERENCES}

1. Morrison, G. H. and Freiser, H., "Solvent Extraction in Analytical Chemistry," 79, John Wiley and Sons, Inc., Philadelphia,Pa. (1957).

2. Smith, E. L. and Page, J. E., J. Soc. Chem. Ind. (London) 67, 48 (1948).

3. Coleman, C. F., Brom, K. B., Moore, J. G., and Crouse, D. J., Ind. Eng. Chem. 50, 1756 (1958).

4. Schindewolf, U., Mass. Inst. Tech. Lab. for Nuclear Science, Progress Report of Fet. 28, 1958, p. 23.

5. Allen, K. A., J. Phys. Chem. 60, 239 (1956).

6. Ibid., 60, 943 (1956).

7. Toid., 62, 1119 (1958).

8. Ioid., 64, 667 (1960).

9. McDowell, W. J. and Allen, K. A., J. Phys. Chem. 63, 747 (1959).

10. AlIen, K. A., I. Am. Chem. Soc. 80, 4133 (1958).

11. Allen, K. A., and McDowell, W. J., J. Phys. Chem. 64, 877 (1960),

12. Fomin, V. V., Zagorets, P. A. and Morgunov. A. F., Zhur. Neorg. Khim. 4, 700, (1959).

13. Carswell, D. J. and Lawrence, J. J., J. Inorg. Nucl. Chem. 11, 69 (1959).

14. Good, M. L. and Bryan, S. E., J. Am. Chem. Soc. 82, 5636 (1960).

15. Good, M. L. and Bryan, S. E., Papers 105 and 106 (Inorganic Division), 138th American Chemical Society Meeting, New York, N. Y. (Sept. 1960).

16. Ichikawa, F. and Urono, S., Bull. Chem. Soc. Japan 33, 569 (1960).

17. Atwood, J. M. and Snyder, W. A., USAEC Report HW-62000 (Oct. 15, 1959).

18. Coleman, C. F. and Brown, K. B., USAEC Report TID-7555, 43 (Nov. 4, 1957'

19. Moore, F. L., USAEC Report ORNL-1314 (July 17, 1952); Anal. Chem. 29, 1660 (Nov. 1957).

20. Ratchford, W. P., Harris, E. H., Jr., Fisher, C. H., and Willits, C. O., Ind. Eng. Chem. 43, 778 (1951). 
21. Ziegler, M., Naturwissenschaften 46, 353 (1959).

22. Petrow, H. G. and co-workers, USAEC Report TID-5772 (April 15, 1960).

23. Katel.aru,.J. and Freiser, H., Paper 37 (Analytical Division) 138th American Chemical Society Meeting, New York, N. Y., (Sept. 1960).

24. Mahlman, H. A., Leddicotte, G. W., and Moore, F. L., Anal. Chem. 26, 1939 (1954).

25. Hicks, H. G., USAEC Report UCRL-5986 (June 1960).

26. Scroggie, L. E. and Dean, J. A., Analytica Chimica Acta 21, 282 (1959).

27. Moore J. G., Blake, C. A., and Schmitt, J. M., USAEC Report ORNL-2346 (July 9, 1957).

28. 'Ireybal, R. E., Ind. Eng. Chem. 51, 378 (1959).

29. Moore, F. L., Anal. Chem. 30, 908 (1958).

30. Thomas, G. and Ingraham, T. R., Canadian Jour. Chem. Eng. 38, 220 (1960).

31. Brown, K. B. and co-workers, USAEC Report ORNL-2099 (May 14, 1956).

32. Tbid., USAEC Report ORNL CF-60-3-136, (April 27, 1960).

33. Boyd, G. E. and Larson, Q. V., J. Phys. Chem. 64, 988 (1960).

34. Moore, J. G., Brown, K. B., and Coleman, C. F., USAEC Report ORNL-1922 (June 24, 1955).

35. Brown, K. B., Coleman, C. F., Crouse, D. J., and Ryon, A. D., USAEC Report ORNL-2268 (April 26, 1957).

36. Keder, W. E., Sheppard, J. C., and Wilson, A. S., J. Inorg. Nucl. Chem. 12, 327 (1960).

37. Schults, W. D., Hobbs, B. B., Blevins, E. L., and Thomason, P. F., USAEC Report ORNI-2776 (Sept. 14, 1959).

38. Moore, F. L., submitted for publication in Analytical Chemistry. ORNL

39. Crouse, D. J., and Brown, K. B., USAEC Report 2720 (July 16, 1959).

40. Ryan, W., Dept. of Scientific and Industrial Research (England), Scientific Report-C.R.L./A.E. $\frac{152}{162}$ (1958).

41. Simard, R., Dept. of Mines and Technical Surveys (Canada), Report $\operatorname{IR}-129$ (1958).

42. Wilson, G. R., USAEC Report ORNL-2866, 82 (Feb. 11, 1960).

43. Mason, E. A. and Vaughen, V. C., USABC Report TID-5720 (Feb. 26, 1960).

44. Moore F. L., unpublished work, ORNL Notebook No. 1428 (1951-1952).

45. Cerra1, E. and Testa, C., Energia Nucleare, 6, 707 (1959).

46. Ioid., 6 , 768 (1959). 
47. Feldman, C., and Pritchard, C. A., USAEC Report, ORNL CF-60-11-23 (Nov. 23, 1960).

48. Leddicotte, G. W. and Moore, F. L., J. Am. Chem. Soc. 14, 1618 (1952).

49. Moore, F. L., unpublished work, ORNL Notebook No. 1635 (Feb. 1954).

50. Ellenburg, J. Y., Leddicotte, G. W., and Moore, F. L., Anal. Chem. 26, 1045 (1954).

51. Hardy, C. J., Scargill, D., and Fletcher. J. M., J. Inorg. Nucl. Chem. I, 257 (1958).

52. Moore, F. L., Anal. Chem. 27, 70 (1955).

53. Gobıe, A. G. and Maddock, A. G., J. Inorg. Nucl. Chem. I, 94 (1958).

54. Casey, A. T. and Maddock, A. G., J. Inorg. Nucl. Chem. 10, 289 (1959).

55. Moore, F. L. and Reynolds, S. A., Anal. Chem. 29, 1596 (1957).

56. Brown, K. B. and co-workers, USAEC Report, ORNL-2874, 22 (Dec. 4, 1959).

57. Bauer, D. J., Rice, A. C., and Barker, J. S., BMRI-5570 (Mar. 22, 1960).

58. Sheppard, J. C., USAEC Report, HW-51958 (Aug. 27, 1957).

59. Surls, J. P., Jr., USAEC Report, UCRL-3209 (Jan. 1956).

60. Wilson, A. S., Paper No. 544 (USA), Second United Nations InternationaI Conference on Peaceful Uses of Atomic Energy, Vol. 17, 348 (Sept. 1958).

61. Winchester, R. S., USAEC Report, LA-2170 (May 31, 1957).

62. Bertocci, U., AERE-R-2933 (May 1959).

63. Brown, K. B. and co-workers, USAEC Report ORNL-CF-60-1-119 (Mar. 4, 1960)

64. Weaver, B. and Hormer, D. E., J. Chem. Eng. Data , 260 (July 1960).

65. Gaitanis, M. J., private communication (Nov. 15, 1960).

66. Taube, M., Report No. 165/v, Polish Academy of Sciences, Institute of Nuclear Research, Warsaw, Poland (Aug. 1960).

67. Moore, F. L., Anal. Chem. 32, 1075 (1960).

68. Kaplan, I., Hildebrandt, R. A., and Ader, M., J. Inorg. Nucl. Chem., 2, 153 (1956).

69. Haeffner, E., Nilssen, C., and Hultgren, A., Proceedings First International Conference on Peaceful uses of Atomic Enerey, V, 2, 498 (1955).

70. Maeck, W. J., Booman, G. I., Elliot, M. C., and Rein, J. E., Anal. Chem. 30, $1902(1958)$.

71. Ibid., 31, 1130 (1959).

72. Bailes, R. H. and co-workers, USAEC Report DOW-147 (Sept. I, 1956).

73. Laux, P. G, and Brown, E. A., USAEC Report TID-7568, Part I, 135 (Sept. 29, 1958). 
74. Webster, R. K. and co-workers, Analytica Chimica Acta 23, 101 (1960).

75. Reynolds, S. A. and Eldridge, J. S., USAEC Report ORNL-CF-57-1-3

(Jan. 3, 1957).

76. Bizot, J. and Trémilion, B., Bull. Soc. Chim., France, No. 1, 122 (1959).

77. Brown, K. B. and co-workers, USAEC Report ORNI-2486 (April 17, 1958).

78. Brown, K. B., "Some New Developments in the Processing of Uranium Ores," Paper No. 8, American Nuclear Society Meeting, Chicago, Ill. (June 1956).

79. Brown, K. B., Crouse, D. J., and Coleman, C. F., "Some New Solvent Extraction Processes for Use in the Hydrometallurgical Treatment of Uranium, Thorium, and Vanadium Ores," American Institute of Mining, Metallurgical, and Petroleum Engineers Meeting, New Orleans, La. (Feb. 27, 1957).

80. Grimes, M. E., "Amine Extraction of Port Radium Leach Liquors," American Institute of Mining, Metallurgical, and Petroleum Engineers Meeting; New York, N. Y. (Feb. 16, 1958).

81. Preuss, A. and Sanders, J., USAEC Report, RMO-2533 (April 1955).

82. Hassial1s, M. D. and co-workers, USABC Report, RMO-4008 (June 1, 1956).

83. Petrow, H. G. and co-workers, USAEC Report, WIN-61 (Aug. 26, 1957).

84. Crouse, D. J. and Brown, K. B., USAEC Report, ORNL-2720 (July 1959).

85. Bellingham, A. I. and Simard, R., Canadian Jour. Chem. Eng., 113 (June 1959).

86. Vaovenko, V. M. and Lazarev, L. N., Zhurn. Neorgan. Khim. 3, 155 (1958).

87. Ellis, D. A., Long, R. S., and Magner, J. E., USAEC Report, DOW-159 (Aug. 1, 1957).

88. Clifford, W. E., Bullwinkel, E. P., McClaine, L. A., and Nobel, P., Jr., J. Am. Cher. Soc. 80, 2959 (1958).

89. Oppermann, R. A., Nystrom, R. F., Nelson, W. O., and Brown, R. E., Int. Jour. Applied Radiation and Isotopes I, 38 (1959).

90. Thomason, P. F., Perry, M. A. and Byerly, W. M., Anal. Chem. 21, 1239 (1949).

91. Heath, R. L., USAEC Report, IDO-16408 (July 1, 1957).

92. Moore, F. L., unpublished work, ORWL Notebook No. 5691, 35 (April 21, $1958)$.

93. Achey, F. A., Chemist Analyst 46, 10 (1957). 